ORNLTM-2000/29

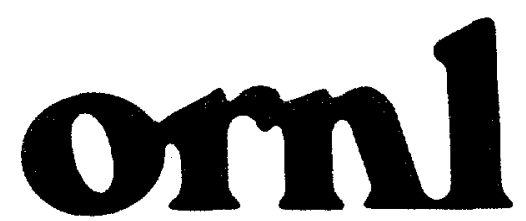

OAK RIDGE

NATIONAL

LABORATORY

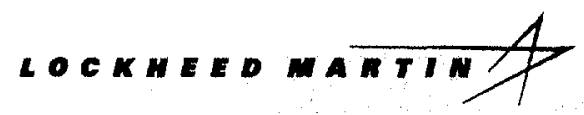

Basic Properties of Reference Crossply Carbon-Fiber Composite

\author{
J. M. Corum \\ R. L. Battiste \\ K. C. Liu \\ M. B. Ruggles
}





\title{
BASIC PROPERTIES OF REFERENCE CROSSPLY CARBON-FIBER COMPOSITE
}

\author{
J. M. Corum \\ R. L. Battiste \\ K. C. Liu \\ M. B. Ruggles
}

February 2000

\author{
Prepared by the \\ OAK RIDGE NATIONAL LABORATORY \\ Oak Ridge, Tennessee 37831-6285 \\ managed by \\ LOCKHEED MARTIN ENERGY RESEARCH CORP. \\ for the \\ U.S. DEPARTMENT OF ENERGY \\ under contract DE-AC05-96OR22464
}




\section{CONTENTS}

ABSTRACT

1. INTRODUCTION

1

2. REFERENCE COMPOSITE

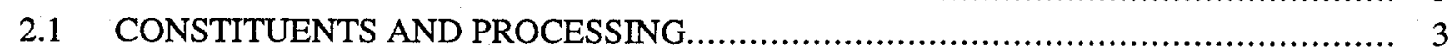

$2.2 \quad$ PLAQUE RECORDS ........................................................................ 5

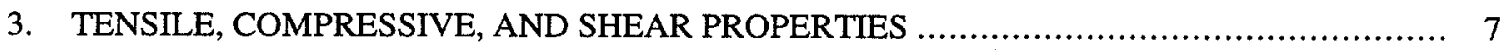

3.1 BASELINE ROOM-TEMPERATURE PROPERTIES ..................................... 7

3.2 DIRECTIONAL DEPENDENCE OF TENSILE PROPERTIES.............................. 9

3.3 VARIABILITY OF PROPERTIES WITH TEMPERATURE ................................ 9

3.4 BASELINE AT-TEMPERATURE PROPERTIES .............................................. 10

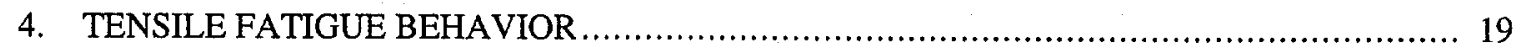

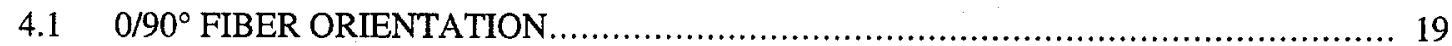

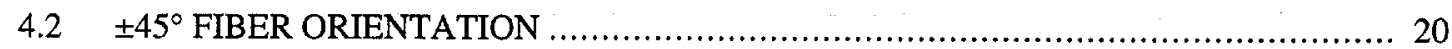

4.3 FATIGUE CURVES WTTH STRESS EXPRESSED AS PERCENT UTS ..................... 20

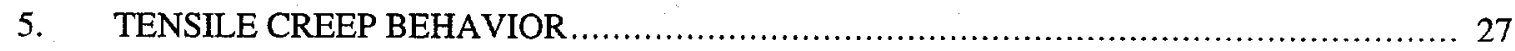

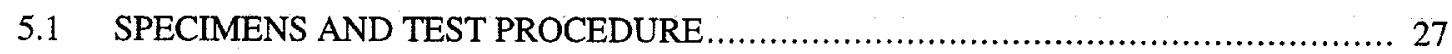

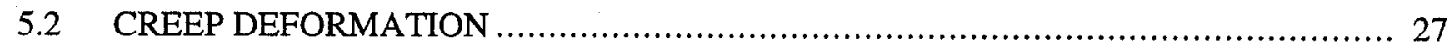

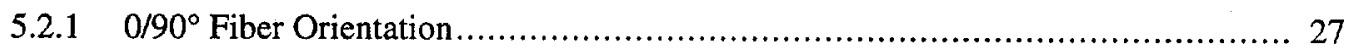

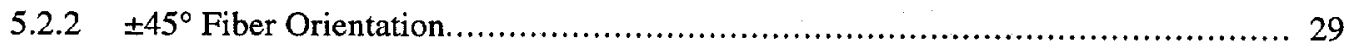

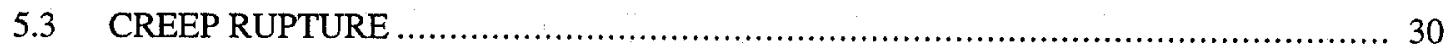

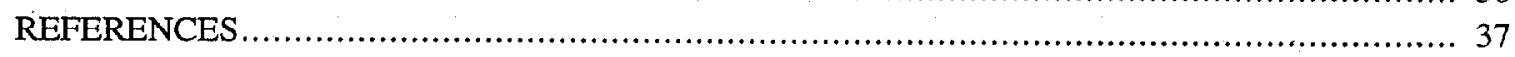

Appendix A. DETERMINATION OF TEMPERATURE DEPENDENCE OF TENSILE, COMPRESSIVE, AND SHEAR PROPERTIES......................................... 39

Appendix B. DAMAGE ACCUMULATION IN TENSILE FATIGUE TESTS ......................... 41 


\title{
BASIC PROPERTIES OF REFERENCE CROSSPLY CARBON-FIBER COMPOSITE
}

\author{
J. M. Corum \\ R. L. Battiste \\ K. C. Liu \\ M. B. Ruggles
}

This report provides basic in-air property data and correlations-tensile, compressive, shear, tensile fatigue, and tensile creep-for a reference carbon-fiber composite being characterized as a part of the Durability of Carbon-Fiber Composites Project at Oak Ridge National Laboratory. The overall goal of the project, which is sponsored by the Department of Energy's Office of Advanced Automotive Materials and is closely coordinated with the Advanced Composites Consortium, is to develop durability-based design guidance for polymeric composites for automotive structural applications. The composite addressed here is a $\pm 45^{\circ}$ crossply consisting of continuous Thornel T300 fibers in a Baydur 420 IMR urethane matrix. Basic tensile, compressive, and shear properties are tabulated for the temperature range from -40 to $120^{\circ} \mathrm{C}$. Fatigue response at room-temperature and $120^{\circ} \mathrm{C}$ are presented, and creep and creep rupture at room temperature only are reported. In all cases, two fiber orientations $-0 / 90^{\circ}$ and $\pm 45^{\circ}$-relative to the specimen axes are addressed. The properties and correlations presented are interim in nature. They are intended as a baseline for planning a full durability test program on this reference composite.

\section{INTRODUCTION}

The purpose of this report is to present, in a readily accessible format, the basic in-air properties-tensile, compressive, shear, tensile fatigue, and tensile creep-of a reference carbon-fiber composite being characterized as part of the Durability of Carbon-Fiber Composites Project at Oak Ridge National Laboratory (ORNL). The project is funded by the U.S. Department of Energy Office of Advanced Automotive Materials and is closely coordinated with the Automotive Composites Consortium (ACC). As the name implies, the project is focused on the durability of carbon-fiber composites for automotive structural applications. An earlier companion project addressed candidate random-glass-fiber automotive composites. Durability-based design criteria were developed and published for a continuous-strand-mat composite and a chopped-fiber composite in the earlier effort.

The reference carbon-fiber composite addressed here is a crossply, $\left[ \pm 45^{\circ}\right]_{3 \mathrm{~S}}$, consisting of $6 \mathrm{~K}$ Thornel T300 continuous fibers in a urethane matrix. The material was supplied by ACC in the form of $.610 \times 610 \times 3-\mathrm{mm}$-thick plaques. The constituents and processing are described in detail in Chap. 2 .

The near-term plan for characterizing and modeling the durability of carbon-fiber composites is to focus on the following sequence of materials, all having the same basic fiber and matrix constituents:

- reference $\left[ \pm 45^{\circ}\right]_{3 \mathrm{~S}}$ crossply composite,

- $\left[0 / 90^{\circ} / \pm 45^{\circ}\right]_{S}$ quasi-isotropic composite, and

- chopped-fiber composite.

Durability issues to be considered in each case include the potentially degrading effects that both cyclic and sustained loadings, exposure to automotive fluids, temperature extremes, and low-energy impacts from 
such things as tool drops and kickups of roadway debris can have on structural strength, stiffness, and dimensional stability.

The basic in-air properties provided for the reference composite, while interim in nature, are intended to serve as a baseline for planning the remaining durability tests for the composite. Two fiber orientations are addressed: $0 / 90^{\circ}$ relative to the specimen axis and $\pm 45^{\circ}$. These orientations result in two extremes of behavior. In the tensile loading case, the behavior of specimens with the $0 / 90^{\circ}$ fiber orientation is fiber dominated, while for specimens with the $\pm 45^{\circ}$ fiber orientation, the behavior is very much matrix dominated.

The specimens, instrumentation, and test procedures used are generally the same as those described in Ref. 1 for random-glass-fiber composites. Hence, they are not described in detail here.

Following the next chapter, which describes the reference composite, Chap. 3 presents the short-time tensile, compressive, and in-plane shẹar properties over the temperature range of -40 to $120^{\circ} \mathrm{C}$. An associated Appendix A describes in more detail the procedure and test data used in each case to develop temperature correlations. Chapter 4 presents tensile fatigue data in the form of S-N curves. Two temperatures, room temperature and $120^{\circ} \mathrm{C}$, are covered. An associated Appendix B presents cyclic stiffness and cyclic strain data for the specimens in an attempt to identify a more appropriate definition of "failure" for the $\pm 45^{\circ}$ specimens than complete specimen separation. Finally, Chap. 5 covers roomtemperature creep and creep rupture. Tentative time-dependent creep equations are developed. 


\section{REFERENCE COMPOSITE}

\subsection{CONSTITUENTS AND PROCESSING*}

The reference carbon-reinforced composite is based on a commercially available fiber widely used in the aerospace industries along with a urea/urethane automotive resin matrix. The carbon fiber is produced by Amoco with the trade name Thornel. Specifically, Thornel T300 in the 6K version was used here. These fibers are produced by a thermal treatment of a polyacrylonitrile (PAN) precursor to produce a continuous-length, high-strength, high-modulus, fiber bundle consisting of 6000 individual filaments. According to the manufacturer's data, these fibers have the following properties.

- Strength-3.20 GPa

- Modulus-228 GPa

- Failure strain-1.4\%

- Filament diameter-7 $\mu \mathrm{m}$

- Density- $1.76 \mathrm{Mg} / \mathrm{m}^{3}$

The fibers were converted into a mat form by Johnson Industries of Phoenix City, Alabama. The mat consisted of two unidirectional plies stitched together in a $\pm 45^{\circ}$ configuration. Each ply of the mat had an areal density of $200 \mathrm{~g} / \mathrm{m}^{2}$. The plies were stitched together with $7 \mathrm{~g} / \mathrm{m}^{2}$ of polyester stitching threads, producing an overall mat areal density of $407 \mathrm{~g} / \mathrm{m}^{2}$.

The matrix resin is a urethane-based material produced by the Bayer Corporation and identified as 420 IMR, where the IMR indicates that the product contains an internal mold release. Conventional polyols and polymeric isocyanates are used with an amine coreactant to produce a cross-linked urea-urethane basic structure. The urea component contributes to the heat resistance of the final composite. With this ureaurethane system, the time required for the liquid-to-solid transformation is of the order of 15-20 s.

The composite plaques were produced via the "Injection-Compression Procedure." For this process, a preform is produced by assembling six of the above described carbon fiber $\pm 45^{\circ}$ mats and introducing them into the mold. After the preform is loaded into the mold, the mold is left open approximately $10-15 \mathrm{~mm}$. The matrix is then produced via the Structural Reaction Injection Molding (SRIM) process in which the two reactive streams, polyol and polymeric isocyanate, are pumped at high pressure into an impingement mixing chamber to quickly produce a uniform mixture of the components. The reacting mixture is then pumped into the partially open mold that contains the reinforcement. The mold is then fully closed. This allows the resin to first flow, with little resistance, across the upper surface of the preform and then, under increasing closing pressure, flow into the thickness direction of the preform. This procedure results in less disturbance of the fiber orientation and produces a more uniform, void-free, distribution of resin through the carbon preform. A 2.5 -min cure time is allowed before the mold is opened and the part ejected. Final postcure was $1 \mathrm{~h}$ in a preheated oven at $130^{\circ} \mathrm{C}$.

The ACC instrumented "shear-edge mold" was used in the manufacture of the carbon-fiber-reinforced plaques. In this mold, the upper mold half telescopes into the lower mold half during closure. In this way, the composite material being molded carries the full molding pressure from the press. With materials of this type, appreciable shrinkage occurs during the chemical reaction. In the shear-edge mold, the upper mold half follows the chemical shrinkage through the telescoping action of the mold halves to produce

\footnotetext{
* Contributed by E. M. Hagerman, Automotive Composites Consortium/General Motors.
} 
smooth molded surfaces. In addition, the mold includes an efficient mold vacuum system that produces up to $710 \mathrm{~mm}$ of vacuum. The vacuum assists in reducing the void content of the molded plaques.

In the plaques produced by the procedures described above, several apparent abnormalities have been noted that are related to the materials and/or processing. The first of these is a reoccurring position-toposition variation in thickness within the molded plaques. Data generated during the testing programs have shown differences between the minimum and maximum thickness within a single plaque of as much as $28 \%$. The instrumented mold used in the molding has displacement transducers at the four corners to observe the motions of mold halves during mold closure. Before molding begins, a zero plane is determined by applying shims between the mold and the press platens such that there is minimal difference between the readings of the displacement transducers when the mold is fully closed and pressurized. Without a carbon fiber preform in place or matrix resin injection, the mold opens and closes in a uniform, parallel motion. The maximum difference observed between displacement transducers during this "dry cycling" is of the order of $0.05-0.15 \mathrm{~mm}$ during the closure and virtually zero when fully closed and pressurized. Based on these setup data, we would anticipate a thickness variation of no more than a few percent in a 3-mm-thick molded plaque.

To understand the material/mold/press interactions that produce the observed thickness variation, a description of the press used in these moldings is required. The press is a 150-ton Newman hydraulic press with 1.2 by $1.8-\mathrm{m}$ platens and is of the four-post design with the upper platen moveable. The ACC mold is about $1-\mathrm{m}$ square and is installed in the center of the press platens. If during the molding operation, the load becomes uncentered, several degrees of freedom in the motions of the upper platen relative to the lower platen become possible. These include front-to-back tilt, left-to-right tilt, rotation about the right front-left rear diagonal, and rotation about the left front-right rear diagonal. In fact, some of the rotation and tilt modes can occur at the same time. The loading force capability, 150 tons, is sufficient to initiate deflections in the posts and can emphasize deflections originating from wear in the platen bushings.

To complete the argument, all that is needed is a mechanism to producc an uncentered load. This occurs as the result of the $\pm 45^{\circ}$ fiber orientation of the preforms and the flow of the resin component during resin injection and subsequent mold closure. If resin is injected into the mold without a preform, a circular puddle is produced that uniformly increases in diameter as the mold is closed. If a $\pm 45^{\circ}$ preform is present, the ply adjacent to the injection port deflects the flow in the fiber direction of that ply. In these systems, flow occurs more easily in the fiber direction than in the cross direction. Secondly, earlier data have suggested that tilt of a few hundredths of a millimeter can direct flow away from the thin dimension side and toward the more open side. A combination of these mechanisms can produce the initial unbalance that becomes more extensive as the mold closes and the molding pressures approach their peak. Peak molding pressures with these materials is of the order $3.5 \mathrm{MPa}$. Data from the displacement transducers during molding operations show maximum corner-to-corner differences of the order of $1 \mathrm{~mm}$ as maximum molding pressure is approached. Added to this scenario is the fact that the time from initial mix of the two components of the urethane system until solidification is only around $20 \mathrm{~s}$, and the viscosity increases exponentially during that period. This latter factor makes it extremely difficult to level any flow imbalance after one has been initiated. It is thought that combinations of these factors produce the observed thickness variations.

The second factor that was observed is some misalignment of the $\pm 45^{\circ}$ fiber orientation. This is also the result of material and/or material and process interactions. In the manufacture of the stitch-bonded mats, the individual fiber bundles are pulled in, through, and around the processing equipment to be placed in the proper orientation before the stitch-bonding operation. It is apparent that during this operation some tension is applied to the fiber mat that is retained in the stitch-bonded product. The stitch-bonded mat is supplied as a $1.25-\mathrm{m}$-wide roll. From that roll, $0.6-\mathrm{m}$ squares are cut to form the preform for the molding 
operation. It has been observed that as a result of cutting the $0.6-\mathrm{m}$ squares, the retained tension in the roll is relieved, which results in a dimensional change from the desired square to a rectangle with dimensions that are a function of the degree of tension in the mat. Attendant to that dimension change is a change in the orientation of the fibers contained in the plies. A second source of misalignment occurs as the liquid urethane components are impacted into the preform mat during the injection stage of the injectioncompression process. In some instances, this can exceed the capability of the stitching fibers to retain the orientation, which results in physically moving fibers away from the desired orientation. In some extreme cases, a football-shaped resin-rich area is formed around the injection port. Obviously, such extreme cases are discarded; however, nearly all plaques and parts manufactured in this way show some degree of fiber movement.

The process described above and the observed abnormalities inherent in such processes tend to illuminate the differences between classic aerospace processing and the high-speed, high-volume processes used in automotive industries. Aerospace processing works with very uniform, thin, 0.1-mm lamellae, which are stacked together in prescribed patterns to fulfill specific applications. These lamellae contain resins that require hours under heat and low pressure to cure and further hours in postcure to produce the final parts. Automolive processing, on the other hand, works with high-pressure high-flow rate processes that are complete in $4 \mathrm{~min}$ or less and are intrinsically more difficult to control relative to fiber orientation and material thickness. More sophisticated fast-acting molding presses with hydraulic leveling can minimize the thickness variation but probably would not result in complete elimination of all the thickness variability.

\subsection{PLAQUE RECORDS}

Table 2.1 is a tabulation of the 55 reference carbon-fiber plaques being used in the ORNL Durability of Carbon-Fiber Composites Project. The three letters in the ACC plaque designation denote the molding run. As can be seen, the plaques came from four different molding runs. At least three different carbonreinforcement rolls were used: TBC-1 through -18 and the TRI plaques used one roll (56112); TBC-19 through -24 used a second roll (64296); the DTB plaques used a third unnumbered roll; and it is not certain what roll was used for the DEV plaques. At least two different batches of resin components were used.

The fiber mat weight and the finished plaque weight were measured in each case. From these measurements, ACC calculated the fiber volume contents given in Table 2.1. The average values for each series are tabulated in Table 2.2 .

The fiber misalignment appeared to average $2^{\circ}$ or $3^{\circ}$ in the TBC and TRI plaques. It was somewhat higher in the DEV plaques (as high as $7^{\circ}$ or $\left.8^{\circ}\right)$, and it was very low $\left(0^{\circ}\right.$ in some cases) in the DTB plaques.

Although the intent was to have a symmetric stacking order of the reinforcement, $\left[ \pm 45^{\circ}\right]_{3 S}$, the order in the first 20 plaques, $\mathrm{Cl}-\mathrm{C} 20$, was unsymmetric, $\left[ \pm 45^{\circ}\right]_{6 \mathrm{~T}}$. This is not thought to have had a significant effect on the in-plane properties presented in this report. 
Table 2.1. Reference carbon-fiber plaques being used in ORNL tests

\begin{tabular}{|c|c|c|c|c|c|}
\hline $\begin{array}{c}\text { ORNL } \\
\text { designation }\end{array}$ & $\begin{array}{c}\mathrm{ACC} \\
\text { designation } \\
\end{array}$ & $\begin{array}{c}\text { Fiber volume } \\
\text { content }(\%)\end{array}$ & $\begin{array}{c}\text { ORNL } \\
\text { designation } \\
\end{array}$ & $\begin{array}{c}\mathrm{ACC} \\
\text { designation } \\
\end{array}$ & $\begin{array}{c}\text { Fiber volume } \\
\text { content (\%) }\end{array}$ \\
\hline $\mathrm{Cl}$ & TBC 1 & 42.7 & $\mathrm{C} 29$ & DEV 57 & 44.4 \\
\hline $\mathrm{C} 2$ & TBC 3 & 44.1 & $\mathrm{C} 30$ & DEV 65 & 44.1 \\
\hline $\mathrm{C} 3$ & TBC 5 & 41.4 & $\mathrm{C} 31$ & DEV 49 & 43.2 \\
\hline $\mathrm{C} 4$ & TBC 6 & 40.5 & $\mathrm{C} 32$ & DTB 9 & 40.7 \\
\hline $\mathrm{C} 5$ & $\mathrm{TBC} 7$ & 42.2 & $\mathrm{C} 33$ & DTB 3 & 38.1 \\
\hline $\mathrm{C} 6$ & TBC 8 & 39.1 & $\mathrm{C} 34$ & TBC 2 & 41.0 \\
\hline $\mathrm{C} 7$ & TBC 9 & 41.5 & C35 & DTB 7 & 39.4 \\
\hline $\mathrm{C} 8$ & TBC 10 & 41.7 & $\mathrm{C} 36$ & DTB 8 & 39.2 \\
\hline $\mathrm{C} 9$ & TBC 11 & 41.2 & $\mathrm{C} 37$ & DTB 18 & 38.3 \\
\hline $\mathrm{C} 10$ & TBC 13 & 41.7 & $\mathrm{C} 38$ & DTB 19 & 39.9 \\
\hline $\mathrm{C} 11$ & TBC 14 & 40.2 & C39 & DTB 10 & 39.7 \\
\hline $\mathrm{C} 12$ & TBC 15 & 41.2 & $\mathrm{C} 40$ & DTB 11 & 38.8 \\
\hline $\mathrm{C} 13$ & TBC 16 & 39.8 & $\mathrm{C} 41$ & DTB 12 & 39.1 \\
\hline $\mathrm{C} 14$ & TBC 17 & 39.5 & $\mathrm{C} 42$ & DTB 14 & 38.1 \\
\hline $\mathrm{C} 15$ & $\mathrm{TBC} 18$ & 42.7 & $\mathrm{C} 43$ & DTB 16 & 38.9 \\
\hline $\mathrm{C} 16$ & TBC 23 & 38.8 & $\mathrm{C} 44$ & DTB 6 & 40.2 \\
\hline $\mathrm{C} 17$ & TBC-24 & 38.6 & $\mathrm{C} 45$ & DEV 48 & 40.7 \\
\hline $\mathrm{C} 18$ & TRI 24 & 43.1 & $\mathrm{C} 46$ & DEV 53 & 44.4 \\
\hline $\mathrm{C} 19$ & TRI 25 & 45.1 & $\mathrm{C} 47$ & DEV 58 & 43.5 \\
\hline $\mathrm{C} 20$ & TRI 29 & 44.4 & $\mathrm{C} 48$ & DEV 62 & 44.6 \\
\hline $\mathrm{C} 21$ & DEV 50 & 44.4 & $\mathrm{C} 49$ & DEV 64 & 45.7 \\
\hline $\mathrm{C} 22$ & DEV 59 & 44.1 & $\mathrm{C} 50$ & DEV 55 & 45.0 \\
\hline $\mathrm{C} 23$ & DEV 47 & 41.8 & $\mathrm{C} 51$ & DTB 20 & 40.2 \\
\hline $\mathrm{C} 24$ & DEV 56 & 44.7 & C52 & DTB 21 & 38.3 \\
\hline $\mathrm{C} 25$ & DEV 60 & 43.8 & $\mathrm{C} 53$ & DTB 23 & 38.9 \\
\hline $\mathrm{C} 26$ & DEV 45 & 39.4 & $\mathrm{C} 54$ & DTB 15 & 38.9 \\
\hline $\mathrm{C} 27$ & DEV 61 & 43.8 & $\mathrm{C} 55$ & DTB 1.7 & 37.6 \\
\hline $\mathrm{C} 28$ & DEV 54 & 44.4 & & & \\
\hline
\end{tabular}

Table 2.2. Average fiber volumes

\begin{tabular}{ccc}
\hline Series & $\begin{array}{c}\text { Average fiber } \\
\text { volume (\%) }\end{array}$ & $\operatorname{COV}^{\mathrm{a}}(\%)$ \\
\hline TBC & 41.1 & 3.5 \\
TRI & 44.3 & 1.7 \\
DEV & 39.0 & 2.2 \\
DTB & 43.5 & 3.7 \\
\hline \multicolumn{3}{l}{ Coefficient of variation (standard deviation as } \\
percent of mean).
\end{tabular}




\section{TENSILE, COMPRESSIVE, AND SHEAR PROPERTIES}

\subsection{BASELINE ROOM-TEMPERATURE PROPERTIES}

Average baseline room-temperature properties determined to date have each come, in most cases, from specimens from several plaques. Best estimates of average properties at other temperatures, which are given in Sect. 3.4, were normalized to the room-temperature averages using the procedures and temperature factors described in Sect. 3.3 .

The average room-temperature properties for the $0 / 90^{\circ}$ and $\pm 45^{\circ}$ fiber orientations are tabulated in Table 3.1, with coefficients of variation, in percent, given in parentheses. The tensile properties came from dogboned specimens, as described in Ref. 1. Averaging extensometers were employed. In the $0 / 90^{\circ}$ case, many tensile specimens intended for other purposes were subjected to virgin stiffness (modulus) checks; those data are included in the Table 3.1 average. Poisson's ratio values came from special tests on specimens with 3.2-mm-gage-length two-gage rosettes on both faces. The compression specimens are also described in Ref. 1, as are the Iosipescu shear specimens that were used. Strain gages were used for strain measurement in both of the latter two types of tests.

Table 3.1. Average room-temperature properties

\begin{tabular}{|c|c|c|}
\hline Property & $0 / 90^{\circ}$ fiber orientation & $\pm 45^{\circ}$ fiber orientation \\
\hline \multicolumn{3}{|l|}{ Tensile } \\
\hline \multirow[t]{2}{*}{ Specimens/plaques } & 224 stiffness & $94 / 25$ \\
\hline & 79 tensile/16 plaques & \\
\hline Elastic modulus, $\mathrm{GPa}$ & $44.9(8.16)$ & $11.2(14.0)$ \\
\hline Poisson's ratio ${ }^{\mathrm{a}}$ & 0.05 & 0.76 \\
\hline Strength, $\mathrm{MPa}$ & $474(11.1)$ & $149(11.1)$ \\
\hline Failure strain, \% & $1.01(12.2)$ & $9.78(24.8)$ \\
\hline \multicolumn{3}{|l|}{ Compressive } \\
\hline Specimens/plaques & $12 / 2^{\mathrm{b}}$ & $6 / 1^{c}$ \\
\hline Elastic modulus, GPa & $50.4(8.92)$ & $13.9(7.08)$ \\
\hline Strength, MPa & $478(6.99)$ & $163(4.59)$ \\
\hline Failure strain; \% & $1.12(17.7)$ & $7.25(19.7)$ \\
\hline \multicolumn{3}{|l|}{ In-plane shear } \\
\hline Specimens/plaques & $15 / 3^{d}$ & $6 / 1^{\mathrm{e}}$ \\
\hline Shear modulus, GPa & $2.96(11.2)$ & $24.2(2.65)$ \\
\hline Shear strength, MPa & $92.8(8.87)$ & $191(9.80)$ \\
\hline Shear failure strain, $\%$ & $11.9(5.59)$ & $0.88(21.2)$ \\
\hline $\begin{array}{l}\text { 0/90 values came from th } \\
\text { three specimens from plaq } \\
\text { b Plaques C4 and C5 } \\
{ }^{c} \text { Plaque C26 } \\
{ }^{d} \text { Plaques } C 1, C 2 \text {, and } C 3 \\
\text { e Plaque C21 }\end{array}$ & mens from plaque $\mathrm{Cl}$ & des came from \\
\hline
\end{tabular}


Table 3.2 tabulates the plaque-average tensile strength and stiffness values. Each average came from at least three specimens. These data allow some assessment of plaque-to-plaque variations to be made. The following general conclusions have been drawn from correlations based on the data in Table 3.2.

Table 3.2. Summary of plaque-average tensile strength and stiffness

\begin{tabular}{|c|c|c|c|c|}
\hline \multirow{2}{*}{ Plaque number } & \multicolumn{2}{|c|}{$0 / 90^{\circ}$ fiber orientation } & \multicolumn{2}{|c|}{ $\pm 45^{\circ}$ fiber orientation } \\
\hline & Stiffness (GPa) & $\mathrm{UTS}^{\mathrm{a}}(\mathrm{MPa})$ & Stiffness (GPa) & UTS (MPa) \\
\hline $\mathrm{C} 1 / \mathrm{TBC} 1$ & 44.7 & 496 & & \\
\hline $\mathrm{C} 2 / \mathrm{TBC} 3$ & 46.6 & 514 & & \\
\hline $\mathrm{C} 3 / \mathrm{TBC} 5$ & 43.7 & 485 & & \\
\hline C4/TBC 6 & 43.2 & 477 & & \\
\hline $\mathrm{C} 5 / \mathrm{TBC} 7$ & 44.4 & 496 & & \\
\hline C6/TBC 8 & & & 10.8 & 132 \\
\hline C9/TBC 11 & & & 10.3 & 139 \\
\hline $\mathrm{C} 11 / \mathrm{TBC} 14$ & & & 10.1 & 126 \\
\hline $\mathrm{C} 12 / \mathrm{TBC} 15$ & 43.2 & 408 & & \\
\hline C13/TBC 16 & 40.3 & 439 & & \\
\hline C15/TBC 18 & 46.2 & 472 & & \\
\hline $\mathrm{C} 16 / \mathrm{TBC} 23$ & & & 10.4 & 112 \\
\hline C17/TBC 24 & & & 10.2 & 108 \\
\hline C18/TRI 24 & 44.6 & 451 & & \\
\hline C19/TRI 25 & 51.3 & 459 & & \\
\hline C20/TRI 29 & & & 13.0 & 126 \\
\hline C21/DEV 50 & 50.7 & 444 & & \\
\hline C22/DEV 59 & 48.0 & 458 & & \\
\hline C23/DEV 47 & 48.4 & 399 & & \\
\hline C24/DEV 56 & & & 12.7 & 161 \\
\hline C25/DEV 60 & 50.4 & 461 & & \\
\hline C26/DEV 45 & & & 15.9 & 173 \\
\hline C27/DEV 61 & 50.3 & 476 & 14.1 & 149 \\
\hline C28/DEV 54 & 50.8 & 504 & 14.2 & 151 \\
\hline C31/DEV 49 & & & 13.8 & 149 \\
\hline C32/DTB 9 & & & 11.1 & 165 \\
\hline C33/DTB 3 & & & 10.3 & 153 \\
\hline $\mathrm{C} 34 / \mathrm{TBC} 2$ & & & 10.7 & 140 \\
\hline C35/DTB 7 & & & 10.3 & 158 \\
\hline C36/DTB 8 & & & 10.5 & 160 \\
\hline C37/DTB 18 & & & 10.5 & 149 \\
\hline C38/DTB 19 & & & 10.4 & 156 \\
\hline C39/DTB 10 & & & 10.5 & 155 \\
\hline C40/DTB 11 & & & 10.6 & 163 \\
\hline C41/DTB 12 & & & 10.4 & 163 \\
\hline C42/DTB 14 & & & 10.1 & 159 \\
\hline C43/DTB 16 & & & 10.1 & 158 \\
\hline C44/DTB 6 & & & 10.8 & 163 \\
\hline C45/DEV 48 & & & 12.3 & 151 \\
\hline
\end{tabular}

${ }^{\mathrm{a}} \mathrm{UTS}=$ ultimate tensile strength. 
- Except for the $\pm 45^{\circ}$ case where the TBC plaques made with carbon roll 64296 appear weaker and the DTB plaques appear stiffer, no molding-run to molding-run or carbon-roll to carbon-roll trends are obvious.

- For both the $0 / 90^{\circ}$ and $\pm 45^{\circ}$ fiber orientations, stiffness varies linearly with fiber volume; strength is weakly dependent on fiber volume in the $0 / 90^{\circ}$ case but shows no obvious dependence in the $\pm 45^{\circ}$ case.

- Strength and stiffness vary linearly with plaque thickness in both cases.

- Unlike the case of the random-glass-fiber composites, any relation between strength and stiffness appears to be both weak and clouded by scatter.

\subsection{DIRECTIONAL DEPENDENCE OF TENSILE PROPERTIES}

Gao and Weitsman ${ }^{2}$ have systematically studied, analytically and experimentally, the variation in tensile properties with fiber orientation in the reference carbon-fiber composite. Multiple tensile tests were performed on specimens cut from a single plaque (C7) at various angles to the $0 / 90^{\circ}$ fiber orientation. Also, the elastic response of the composite was predicted using micromechanics and laminated plate theory.

Figure 3.1 depicts typical measured stress-strain curves for various orientation angles. The response in the nonlinear range is highly sensitive to orientation. Figure 3.2 illustrates the variation in strength with orientation.

The elastic response at all orientations was predicted closely by the well-established laminated plate theory. Figure 3.3 compares the predicted elastic modulus and Poisson's ratio variations with average measured values at various fiber orientations. The agreement is very good. The predicted values of elastic modulus, E, and shear modulus, G, reported by Gao and Weitsman for the $0 / 90^{\circ}$ and $\pm 45^{\circ}$ orientations agree well with the overall averages reported in Table 3.1 .

The conclusion is that the reference carbon-fiber composite is predictably well-behaved as a crossply laminate.

\subsection{VARIABILITY OF PROPERTIES WITH TEMPERATURE}

The basic approach used to determine properties over the temperature range from -40 to $120^{\circ} \mathrm{C}$ is as follows. Ideally, specimens from a single plaque are tested at various temperatures (multiple tests at each temperature). From these, correlations are developed that describe the variation of each property with temperature. Finally, these correlations are used to calculate factors by which room-temperature properties can be multiplied to yield estimates of the properties at other temperatures. This approach avoids the otherwise large testing effort that would be required to generate overall average properties and plaquespecific properties over the temperature range of interest. The factors can be used with the roomtemperature averages in Table 3.1 to estimate overall average properties, and they can be used with the plaque-average room-temperature tensile properties in Table 3.2 to estimate the properties of a specific plaque at another temperature.

Only the resulting factors are presented in this section. The data used to generate the factors are discussed in Appendix A.

Tensile stress-strain curves, shown in Fig. 3.4 for various temperatures and for both the $0 / 90^{\circ}$ and the $\pm 45^{\circ}$ fiber orientations, illustrate the general effect of temperature on behavior. The $0 / 90^{\circ}$ response is fiber dominated, and the stress-strain response is essentially linear up to failure. In fact, the $-40,23$, and $50^{\circ} \mathrm{C}$ 
curves shown are slightly concave upward, presumably due to straightening of the fibers; the $120^{\circ} \mathrm{C}$ curve does bend downward very slightly. In contrast to the $0 / 90^{\circ}$ case, the $\pm 45^{\circ}$ response is matrix dominated. In-plane and interlaminar shear deformations and failure (scissoring) occur progressively earlier as the temperature is increased.

Table 3.3 gives the modulus and strength temperature multiplication factors for -40 and $120^{\circ} \mathrm{C}$. The value at $23^{\circ} \mathrm{C}$ is 1.0 in each case. The factors are plotted in Figs. 3.5 and 3.6, for fibers oriented at $0 / 90^{\circ}$ and $\pm 45^{\circ}$, respectively, relative to the specimen axes.

Table 3.3. Temperature multiplication factors for determining at-temperature modulus and strength from room-temperature values

\begin{tabular}{|c|c|c|c|c|}
\hline \multirow{3}{*}{ Property } & \multicolumn{4}{|c|}{ Multiplication factor } \\
\hline & \multicolumn{2}{|c|}{$0 / 90^{\circ}$} & \multicolumn{2}{|c|}{ $\pm 45^{\circ}$} \\
\hline & $-40^{\circ} \mathrm{C}$ & $120^{\circ} \mathrm{C}$ & $-40^{\circ} \mathrm{C}$ & $120^{\circ} \mathrm{C}$ \\
\hline \multicolumn{5}{|l|}{ Tension } \\
\hline Modulus & 1.00 & 0.90 & 1.29 & 0.55 \\
\hline Strength & 1.00 & 0.82 & 1.29 & 0.55 \\
\hline \multicolumn{5}{|l|}{ Compression } \\
\hline Modulus & 1.05 & 0.80 & 1.32 & 0.50 \\
\hline Strength & 1.10 & 0.41 & 1.32 & 0.50 \\
\hline \multicolumn{5}{|l|}{ Shear } \\
\hline Modulus & 1.18 & 0.26 & 1.26 & 0.60 \\
\hline Strength & 1.18 & 0.26 & 1.35 & 0.46 \\
\hline
\end{tabular}

Note that for tension and compression, fiber behavior dominates the $0 / 90^{\circ}$ behavior, while matrix behavior dominates the $\pm 45^{\circ}$ direction. These roles are reversed in the shear case; the $\pm 45^{\circ}$ behavior is fiber dominated. With this in mind, it is observed that in the matrix-dominated cases, the multiplication factors are always the same for strength and stiffness. For the fiber-dominated cases, the strength factors at elevated temperatures are always less than the stiffness factors.

\subsection{BASELINE AT-TEMPERATURE PROPERTIES}

Best estimates of the overall average properties at $-40,23$, and $120^{\circ} \mathrm{C}$ are summarized in Tables 3.4 and 3.5 for the $9 / 90^{\circ}$ and $\pm 45^{\circ}$ fiber orientations, respectively. With the exception of the tensile Poisson's ratio values, the properties in these tables were all derived by multiplying the average room-temperature properties in Table 3.1 by the factors from Table 3.3. The Poisson's ratio values are averages from actual at-temperature tests of the same specimens as used for the room-temperature values. Very low loads were used to assure that damage was not introduced at each temperature. 
Table 3.4. Average properties for $0 / 90^{\circ}$ fiber orientation

\begin{tabular}{lccc}
\hline Property & \multicolumn{3}{c}{ Temperature $\left({ }^{\circ} \mathrm{C}\right)$} \\
\cline { 2 - 4 } & -40 & 23 & 120 \\
\hline Tension & & & \\
Modulus, GPa & 44.9 & 44.9 & 40.4 \\
Poisson's ratio & 0.70 & 0.76 & 0.87 \\
Strength, MPa & 474 & 474 & 389 \\
Failure strain, \% & - & 1.01 & - \\
& & & \\
Compression & & & 40.3 \\
Modulus, GPa & 52.9 & 50.4 & 196 \\
Strength, MPa & 526 & 478 & - \\
Failure strain, \% & - & 1.12 & \\
& & & 0.770 \\
Shear & & & - \\
Modulus, GPa & 3.49 & 92.8 & -1 \\
Strength, MPa & 110 & 11.9 & \\
Failure strain, \% & - & & \\
\hline
\end{tabular}

Table 3.5. Average properties for $\pm 45^{\circ}$ fiber orientation

\begin{tabular}{lccc}
\hline \multirow{2}{*}{ Property } & \multicolumn{3}{c}{ Temperature $\left({ }^{\circ} \mathrm{C}\right)$} \\
\cline { 2 - 4 } & -40 & 23 & 120 \\
\hline Tension & & & \\
Modulus, GPa & 14.4 & 11.2 & 6.16 \\
Poisson's ratio & 0.05 & 0.05 & 0.04 \\
Strength, MPa & 192 & 149 & 82.0 \\
Failure strain, \% & - & 9.78 & - \\
& & & \\
Compression & 18.3 & 13.9 & 6.95 \\
Modulus, GPa & 215 & 163 & 81.5 \\
Strength, MPa & - & 7.25 & - \\
Failure strain, \% & & & \\
& & & 14.5 \\
Shear & 30.5 & 24.2 & 87.9 \\
Modulus, GPa & 258 & 191 & - \\
Strength, MPa & - & 0.88 & \\
Failure strain, \% & & & \\
\hline
\end{tabular}




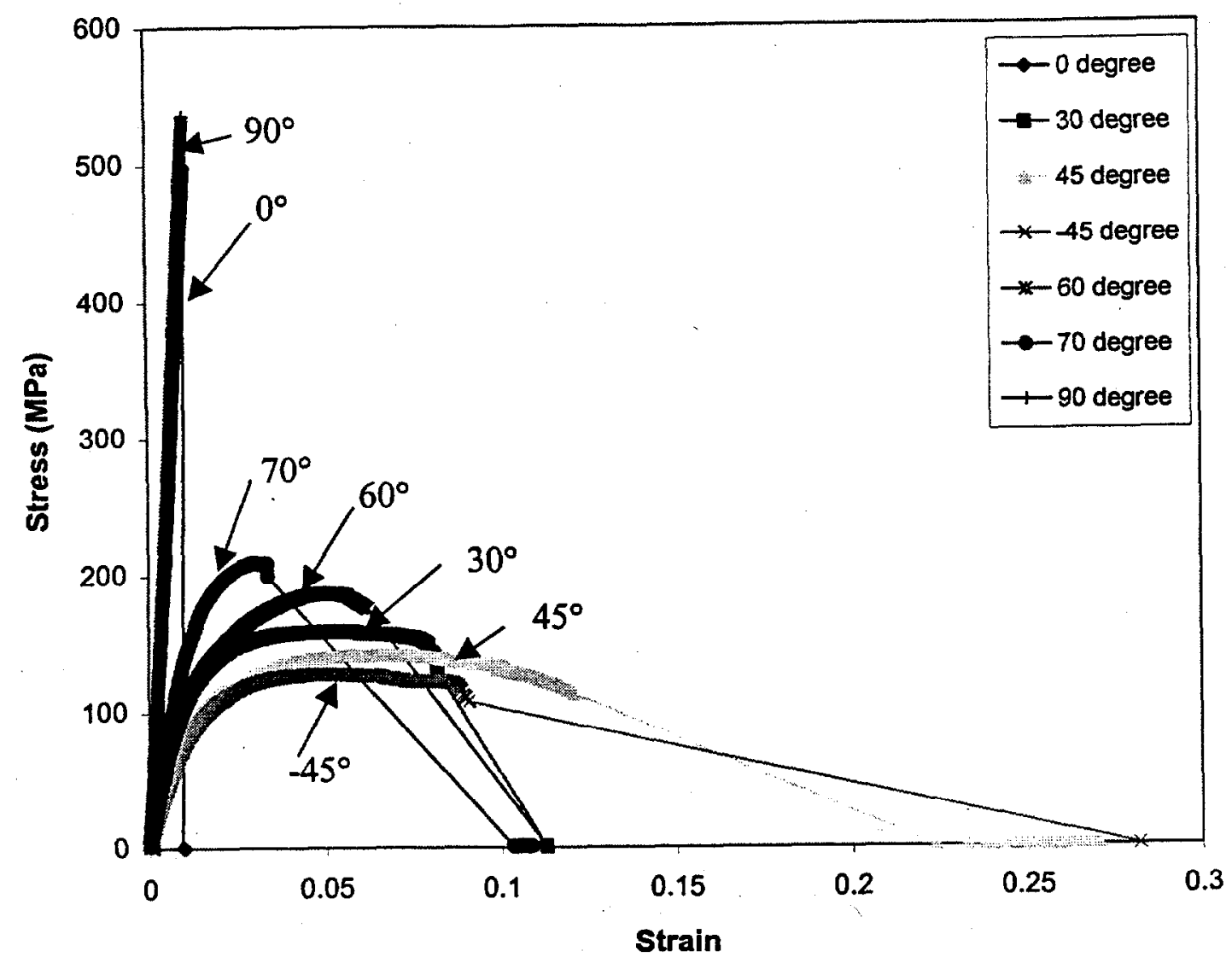

Fig. 3.1. Typical stress-strain response to failure at various orientation angles. Source: Ref. 2. 


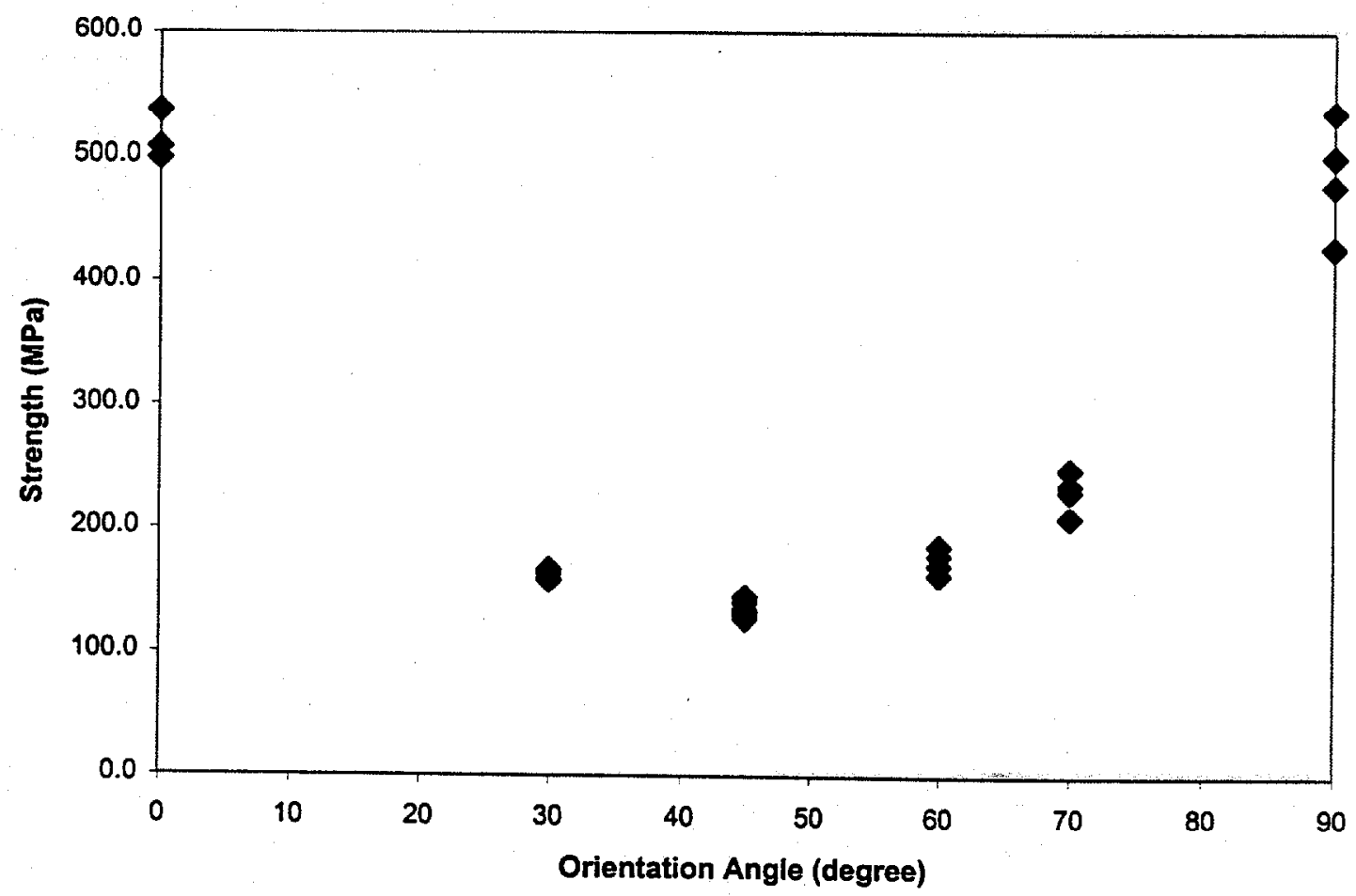

Fig. 3.2. Tensile strength vs orientation angle. Source: Ref. 2 . 


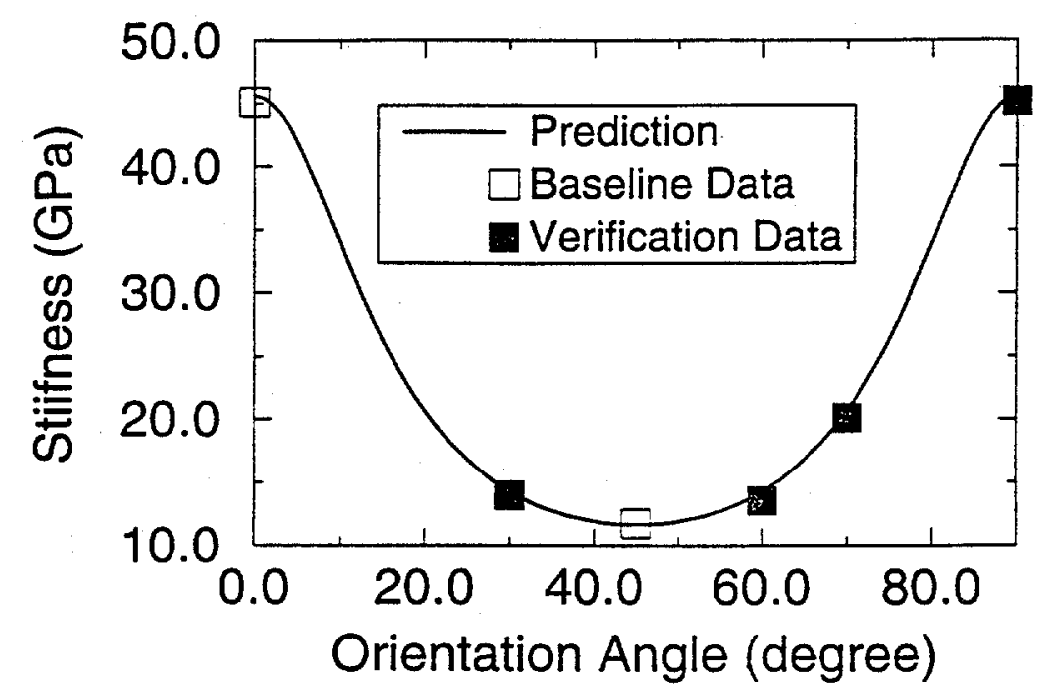

(a) Stiffness

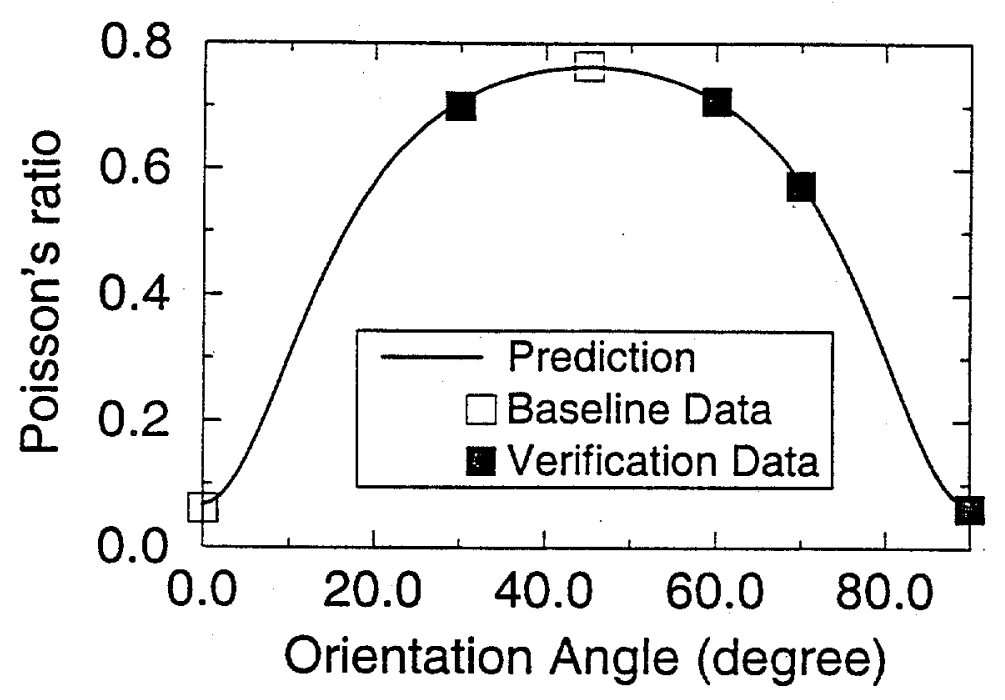

(b) Poisson's ratio

Fig. 3.3. Measured and predicted variation of elastic properties with orientation. Source: Ref. 2 . 


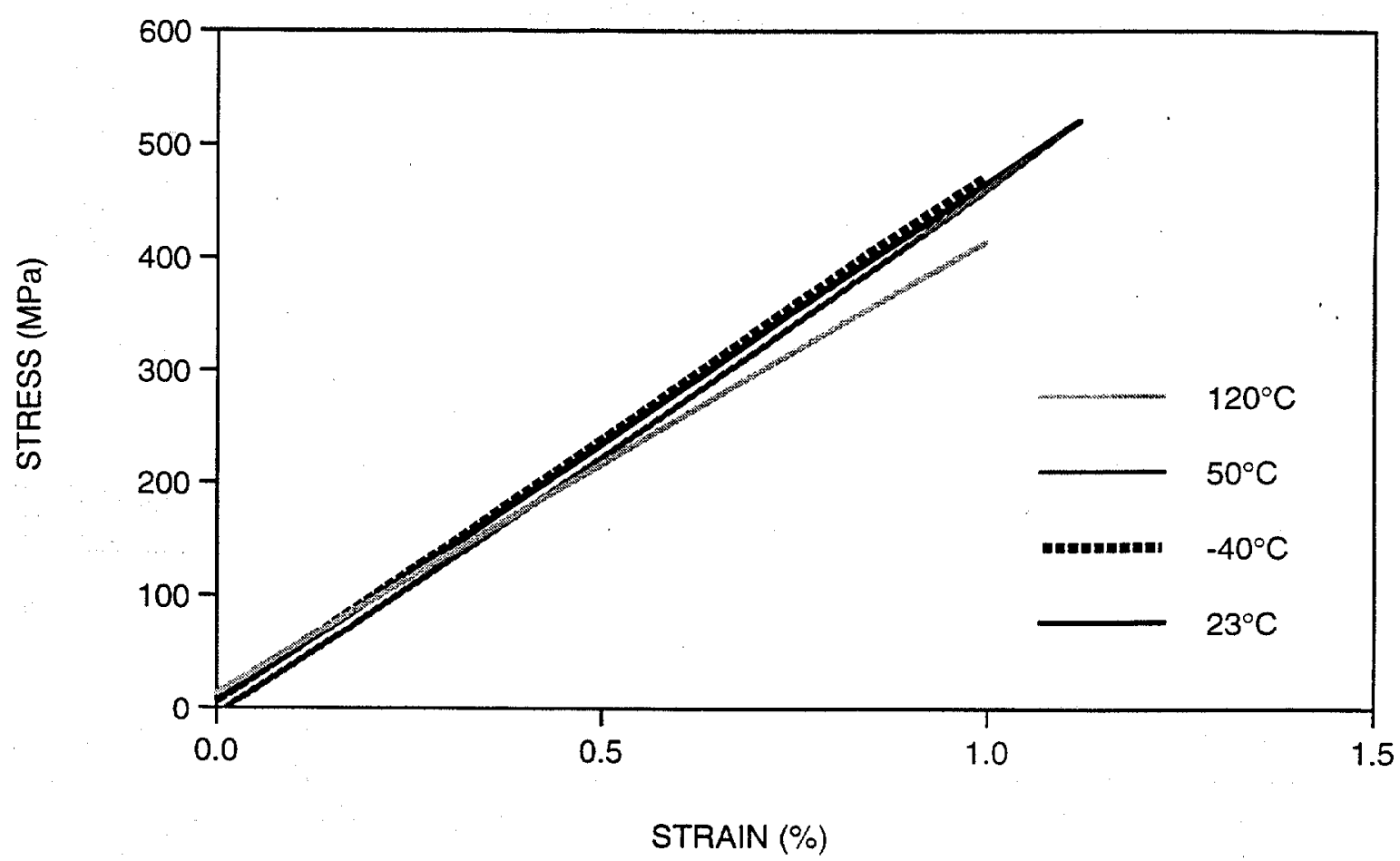

(a) $0 / 90^{\circ}$

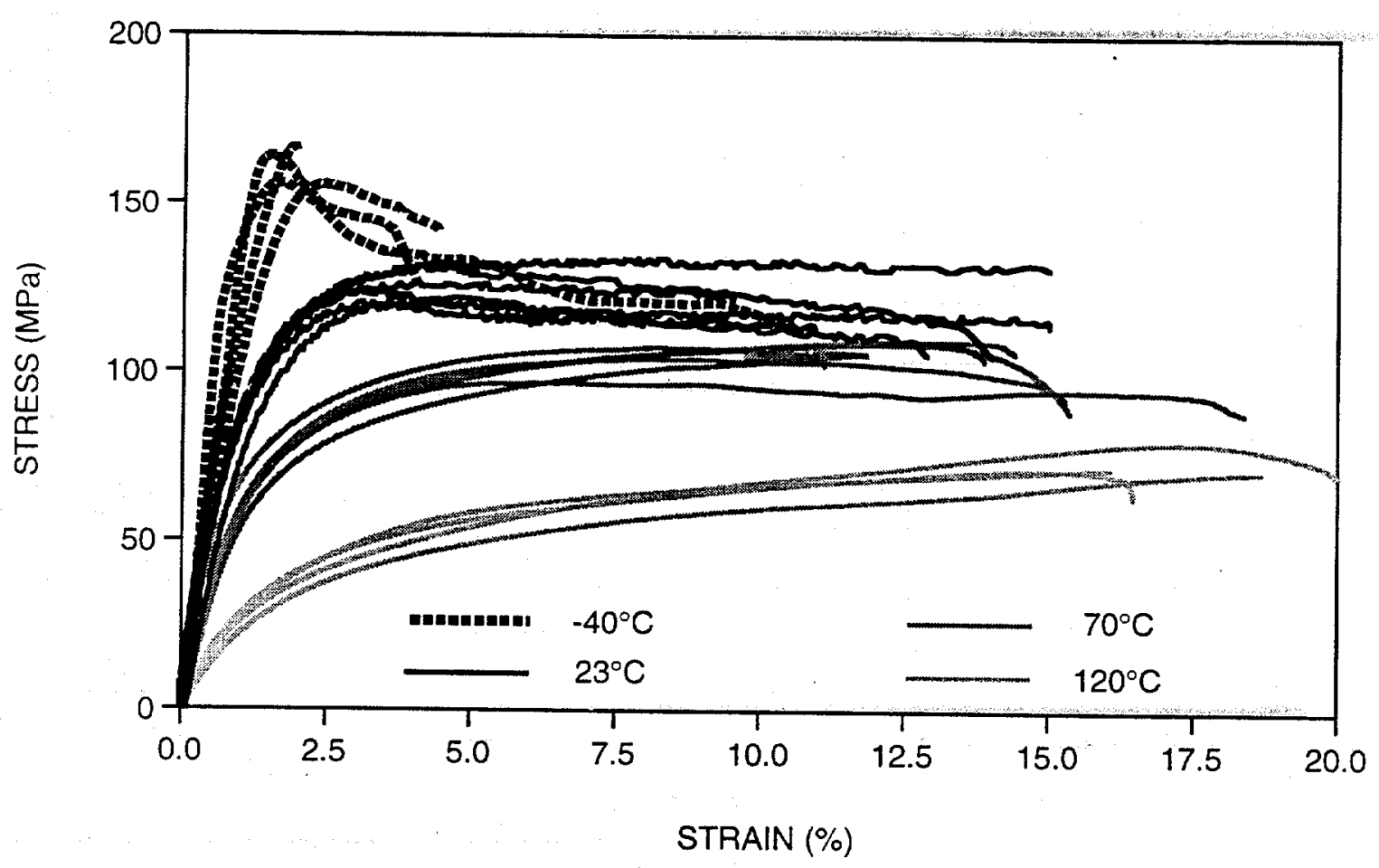

(b) $\pm 45^{\circ}$

Fig. 3.4. Typical tensile stress-strain curves to failure at various temperatures. 


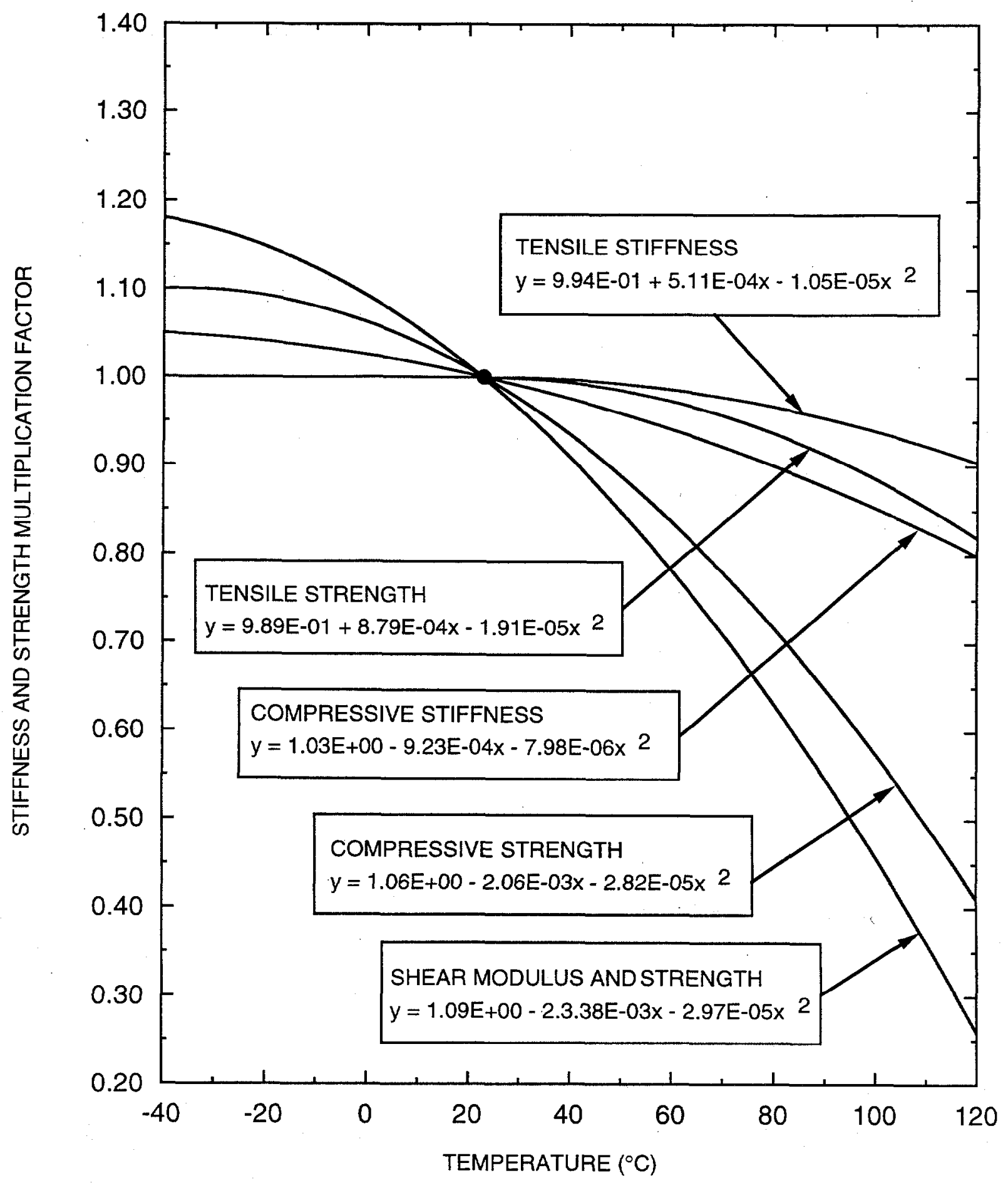

Fig. 3.5. Temperature multiplication factors for fibers oriented at $0 / 90^{\circ}$ relative to specimen axes. 


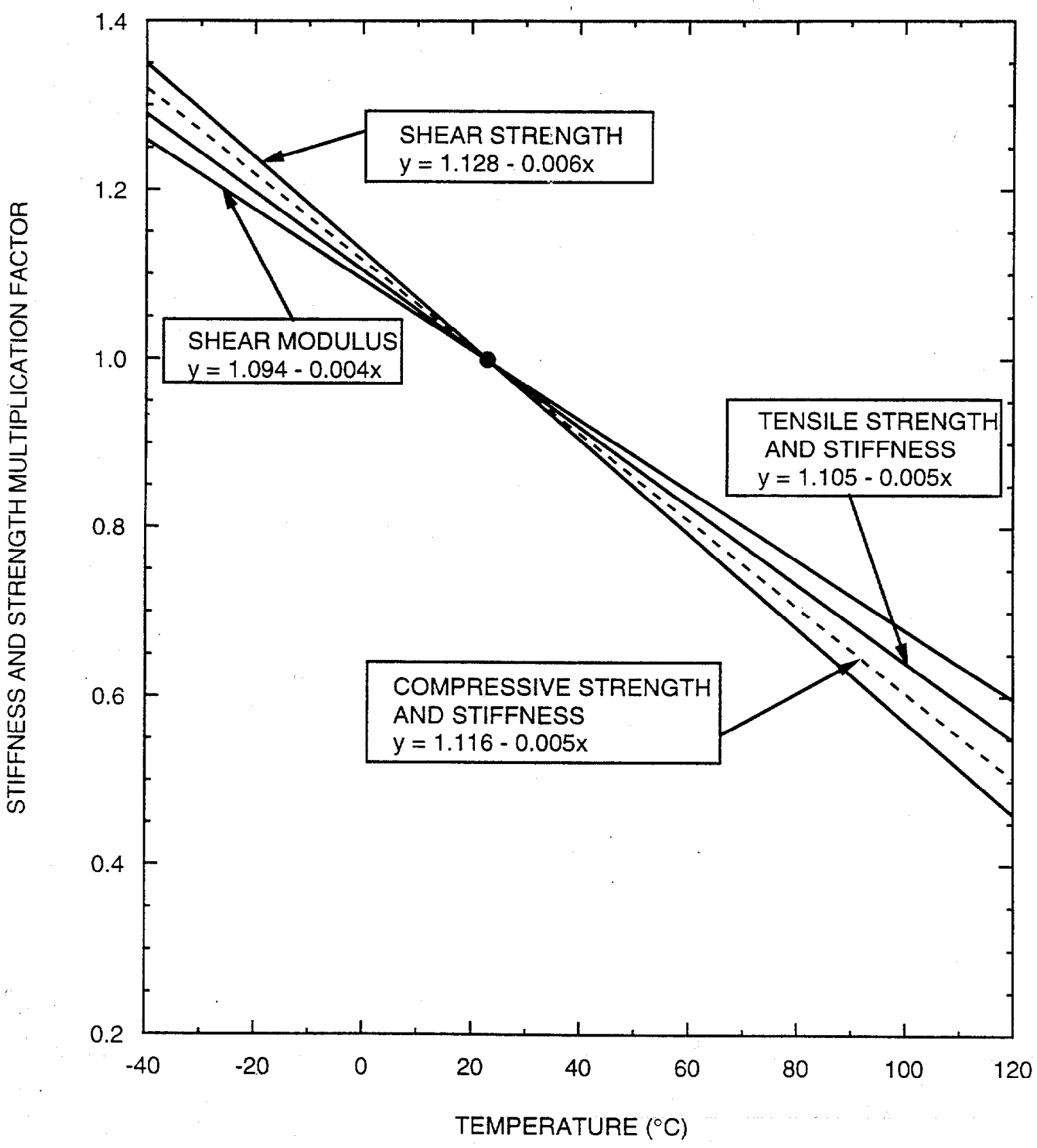

Fig. 3.6. Temperature multiplication factors for fibers oriented at $\pm 45^{\circ}$ relative to specimen axes. 


\section{TENSILE FATIGUE BEHAVIOR}

Tensile fatigue tests have been performed at room temperature and $120^{\circ} \mathrm{C}$ for specimens having both the $0 / 90^{\circ}$ and the $\pm 45^{\circ}$ fiber orientations. The ratio of minimum to maximum cyclic stress, $R$, was 0.1 in all cases. The dogboned-shaped specimen described in Ref. 1 was used. The frequency used varied with stress in accordance with the following relation, recommended by ACC and given in Ref. 1:

$$
\mathrm{f}=\left(\mathrm{kS}_{\mathrm{ult}}\right) /\left(\mathrm{S}_{\max }-\mathrm{S}_{\min }\right)
$$

where $\mathrm{k}$ was $3 \mathrm{~Hz}, \mathrm{~S}_{\mathrm{utt}}$ is the UTS of the composite, $S_{\max }$ is the maximum stress in the cycle, and $S_{\min }$ is the minimum cyclic stress $\left(\mathrm{S}_{\min }=0.1 \mathrm{~S}_{\max }\right)$.

In the case of specimens having fibers aligned at $0 / 90^{\circ}$ to the specimen axes, measured strains remained small throughout the fatigue tests at both room temperature and $120^{\circ} \mathrm{C}$. Failures at both temperatures occurred as sudden breaks, so the numbers of cycles to failure were clearly defined." This was not the case in specimens having a $\pm 45^{\circ}$ fiber orientation. There, in-plane stresses resulted in mixed-mode failures (due to normal and shear stresses) within the plies followed by interlaminar shear failures between the plies (see Fig. 4.1). This resulted in large strains and necking due to scissoring and attendant fiber rotation. In the room-temperature tests, where temperature was not controlled, internal friction led to specimen heating, especially at the higher stresses. At $120^{\circ} \mathrm{C}$, actual failure into two pieces did not occur; in that case, the tests were stopped when the machine stroke reached $13 \mathrm{~mm}$. Thus, for the $\pm 45^{\circ}$ specimens, an alternative definition of failure is required. One possibility is developed in Appendix B and used in this chapter. Appendix B describes the measured variations in stiffness and maximum cyclic strain with number of cycles for both $0 / 90^{\circ}$ and $\pm 45^{\circ}$ fiber orientations.

\subsection{0/90 ${ }^{\circ}$ FIBER ORIENTATION}

Fatigue results, in the form of S-N curves at room temperature and at $120^{\circ} \mathrm{C}$, are shown in Fig. 4.2. Twenty-one tests on specimens from three plaques (C3, C10, and $\mathrm{C} 15)$ were performed at room temperature. At $120^{\circ} \mathrm{C}$, twenty-five tests on specimens from three plaques (C3, C15, and $\left.\mathrm{C} 18\right)$ were conducted. As measured by the coefficients of determination, $r^{2}$, of the curve fits, the scatter is smaller than observed earlier for the random-glass-fiber composites, ${ }^{3,4}$ and it is smaller than that observed in the following section for $\pm 45^{\circ}$ specimens. This is because the composite is highly fatigue resistant in the $0 / 90^{\circ}$ direction, especially at room temperature. The stress levels involved are close to the ultimate strength, indicating that fatigue is unlikely to be a problem when cyclic stresses coincide with the fiber orientation. Note that at the highest stress level at room temperature, the resulting numbers of cycles to failure vary by more than four decades. This fatigue response at stresses approaching the UTS is consistent with the observations reported elsewhere. ${ }^{5}$

If the stress levels in Fig. 4.2 are adjusted to account for the thickness variations discussed earlier, the scatter actually becomes slightly worse at both temperatures. Thus, thickness variations alone do not account for the large scatter.

\footnotetext{
* About one-half of the $0 / 90^{\circ}$ specimens exhibited some axial splitting in the $0^{\circ}$ surface ply prior to breaking. These splits began in the radius regions. Their presence or absence did not seem to correlate with temperature, stress, or cyclic life.
} 
In design criteria for cyclic loadings, it is desirable to ensure that the stiffness loss during cycling does not exceed $10 \%$. The data presented in Appendix B indicate that the stiffness loss in $0 / 90^{\circ}$ specimens remains well below $10 \%$ all the way to failure.

\section{$4.2 \pm 45^{\circ}$ FIBER ORIENTATION}

Figure 4.3 compares the S-N curves for the $0 / 90^{\circ}$ specimens, as described in the previous section, with those for the $\pm 45^{\circ}$ specimens. The fatigue strengths of the latter specimens are significantly lower than those for the $0 / 90^{\circ}$ specimens, reflecting the lower UTS. The fatigue resistance is also less. As previously mentioned, the $120^{\circ} \mathrm{C}$ points for the $\pm 45^{\circ}$ orientation are somewhat arbitrary because they represent reaching a machine stroke of $13 \mathrm{~mm}$, not complete failure. The room-temperature $\pm 45^{\circ}$ curve does reflect complete failure into two pieces, but only after the accumulation of large axial and transverse strains (necking).

Figure 4.4 is a replot of the $\pm 45^{\circ} \mathrm{S}-\mathrm{N}$ curves that includes the curve fit equations and coefficients of determination. Twenty-seven tests on specimens from three plaques $(\mathrm{C} 9, \mathrm{C} 16$, and $\mathrm{C} 17)$ were performed at room temperature. At $120^{\circ} \mathrm{C}$, fourteen tests on specimens from three plaques $(\mathrm{C} 9, \mathrm{C} 16$, and $\mathrm{C} 17)$ were performed. Three of the latter tests were runouts and are thus not shown in Fig. 4.4, although they are subsequently used in Fig. 4.5.

As in the $0 / 90^{\circ}$ case, normalizing the stresses in Fig. 4.4 by specimen thickness actually leads to lower coefficients of determination for both temperatures.

Because the large attendant strains in the $\pm 45^{\circ}$ tests are far beyond what would be tolerated in design, a definition of failure more directly related to functional integrity is needed for the $\pm 45^{\circ}$ orientation. One possibility is the number of cycles to a $10 \%$ stiffness reduction. At room temperature, this leads to a reasonable S-N curve. However, at $120^{\circ} \mathrm{C}$, it does not. As reported in Appendix B, the stiffness in $120^{\circ} \mathrm{C}$ tests dropped more than $10 \%$ in the first few cycles, except at the lowest stress lcvcls, where it actually increased. An alternative definition suggested in Appendix B is to use the number of cycles at which the plot of maximum cyclic strain begins to increase rapidly. This point is defined by a $0.2 \%$ offset method, which is described in Appendix B.

Figure 4.5 shows the S-N curves defined by this method (filled symbols and solid lines) compared with those from Fig. 4.4." The room temperature reduced curve in Fig. 4.5 is nearly the same as that defined by a $10 \%$ stiffness drop. Thus, the curves in Fig. 4.5 seem reasonable for use, with adequate safety factors, for design.

\subsection{FATIGUE CURVES WITH STRESS EXPRESSED AS PERCENT UTS}

The plaque-average UTS values that were tabulated in Table 3.2 vary significantly from plaque to plaque, especially for the $\pm 45^{\circ}$ fiber orientation. This variation carries over into fatigue strength; specimens from plaques with higher UTS values generally exhibit higher fatigue strength. Thus, it would be expected that expressing the maximum cyclic stress as a percentage of the appropriate plaque UTS would improve the fatigue correlations.

Figure 4.5 is a plot of the room-temperature $0 / 90^{\circ}$ and $\pm 45^{\circ}$ tensile fatigue curves with stress expressed as percent UTS. Comparing the coefficients of determination given in Fig. 4.5 with that given in Fig. 4.1 for the $0 / 90^{\circ}$ orientation and in Fig. 4.3 for the $\pm 45^{\circ}$, orientation, indicates there is a modest improvement in both cases.

\footnotetext{
* Data for applying the $0.2 \%$ offset definition were not available for all tests.
} 


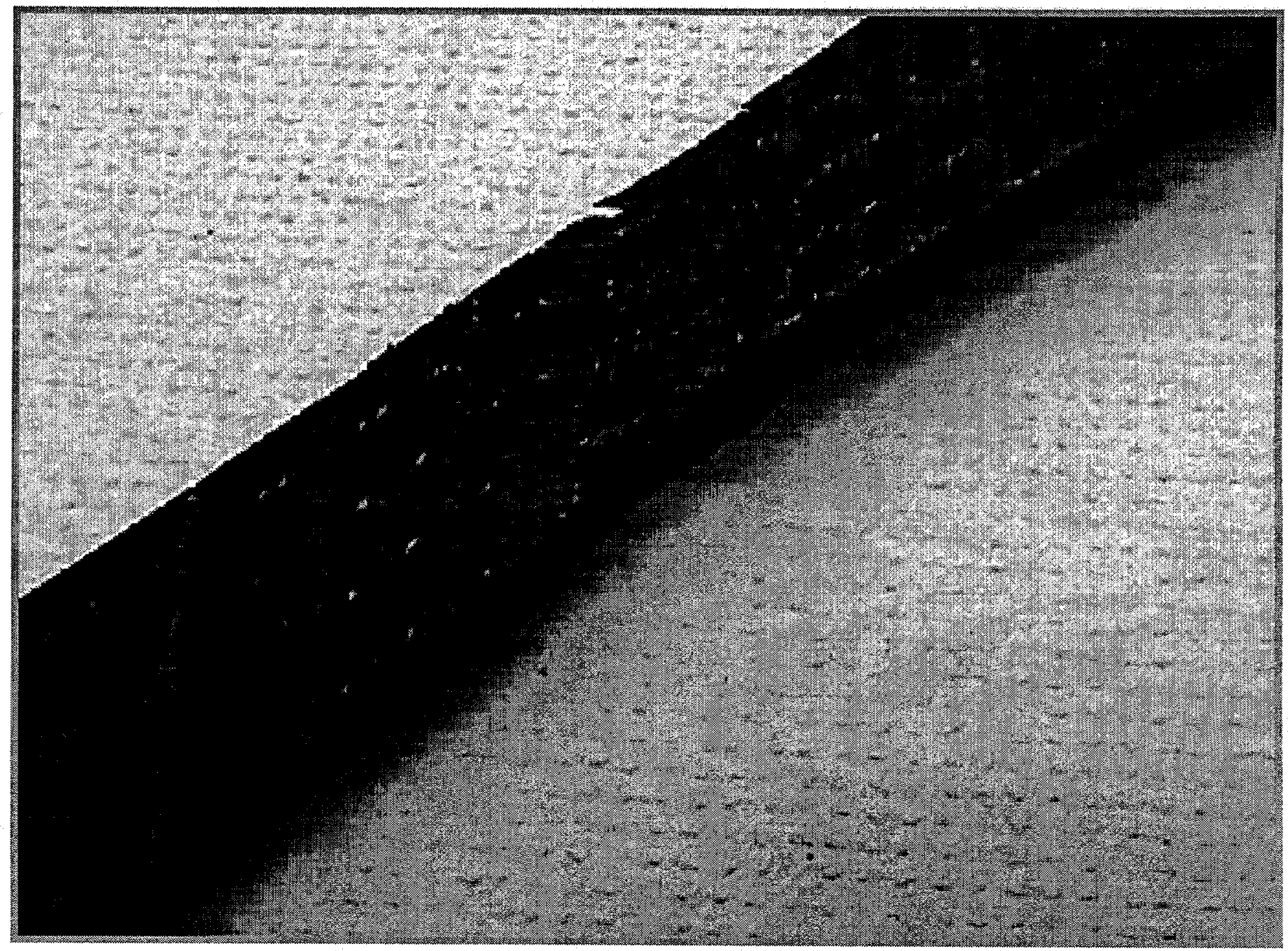

Fig. 4.1. Fatigue specimen with $\pm 45^{\circ}$ fiber orientation, showing ply failures and interlaminar shear failures. 


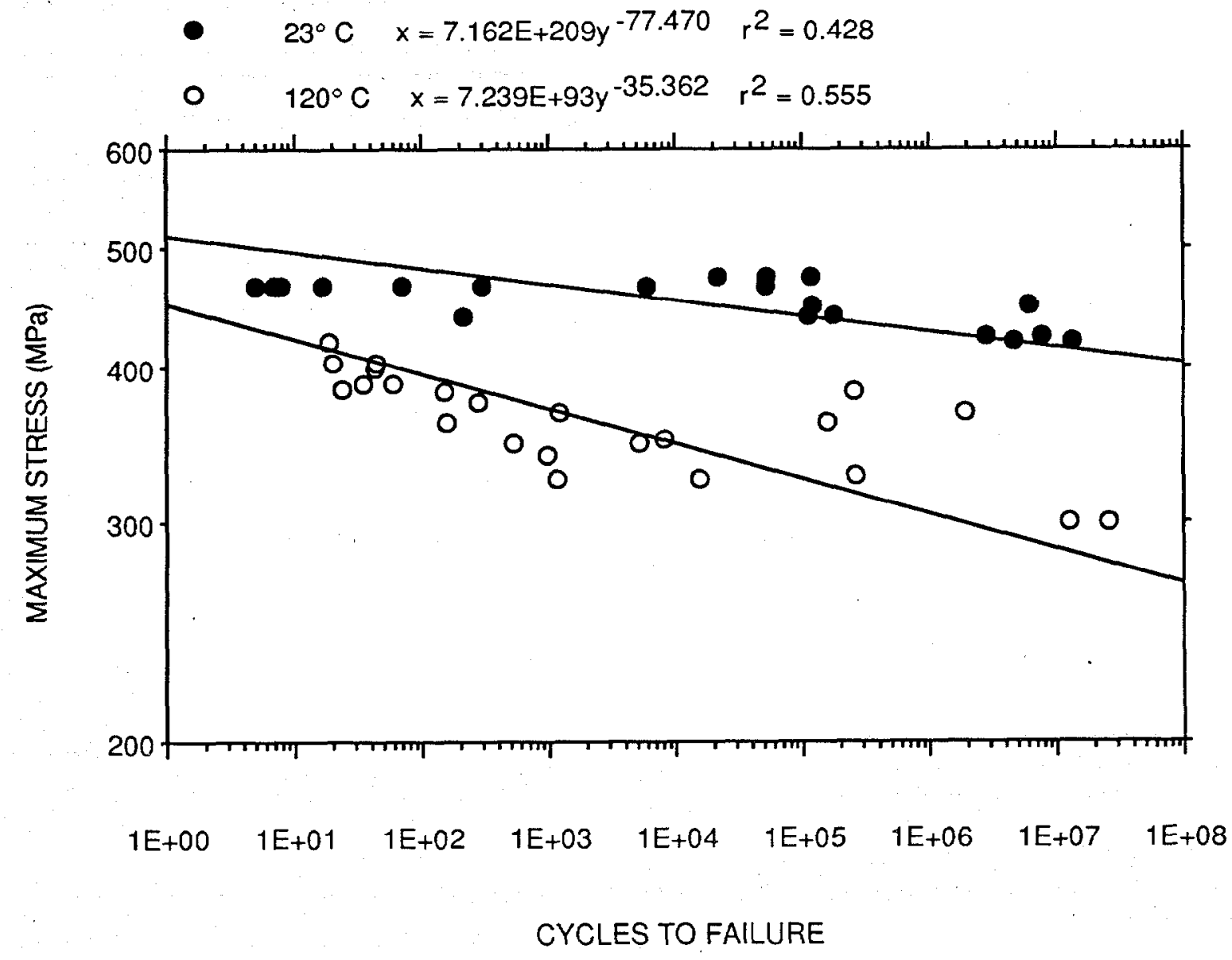

Fig. 4.2. Room-temperature and $120^{\circ} \mathrm{C}$ fatigue curves for specimens with $0 / 90^{\circ}$ fiber orientation. 


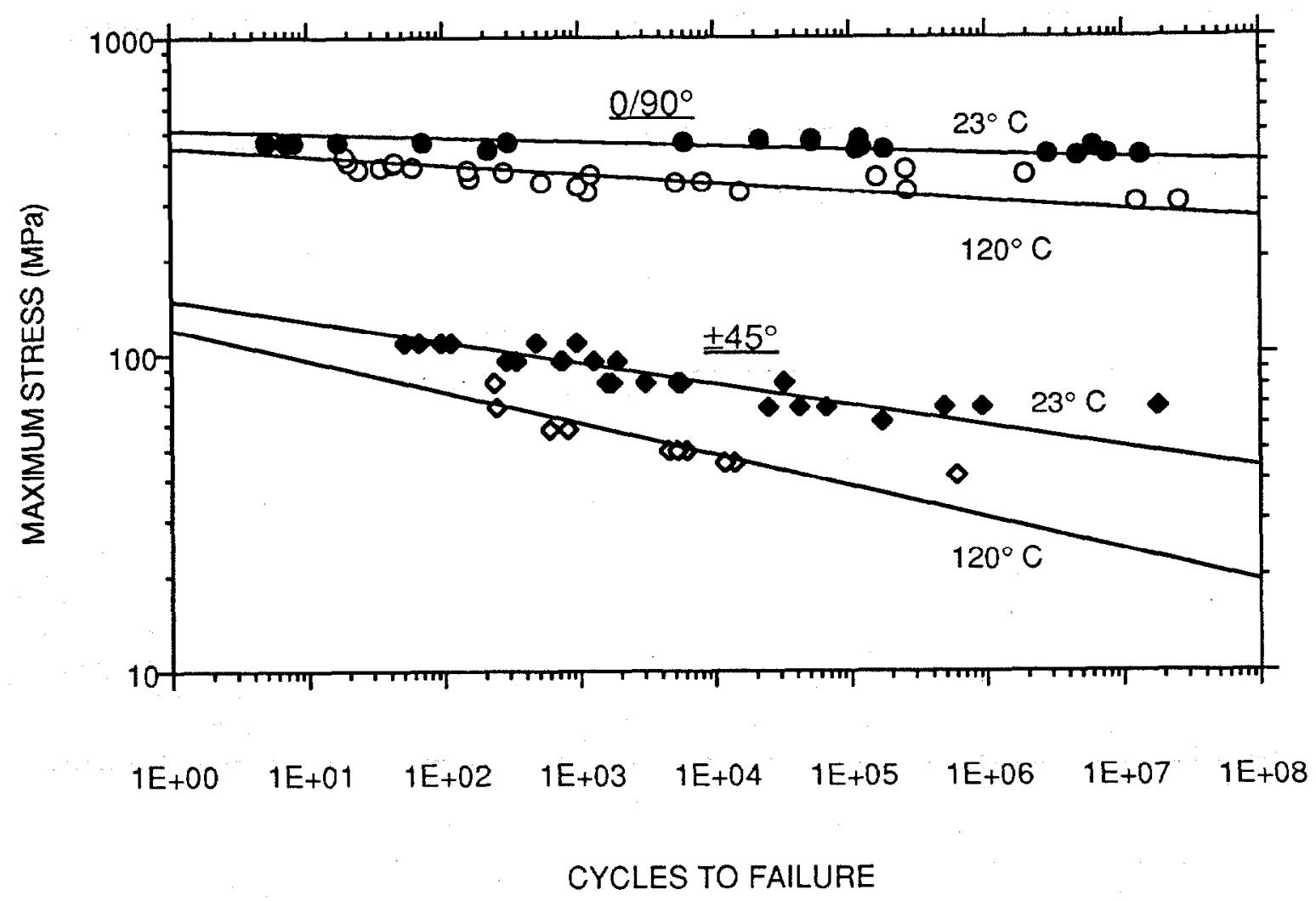

Fig. 4.3. Comparison of $\pm 45^{\circ}$ fatigue curves with $0 / 90^{\circ}$ curves. 


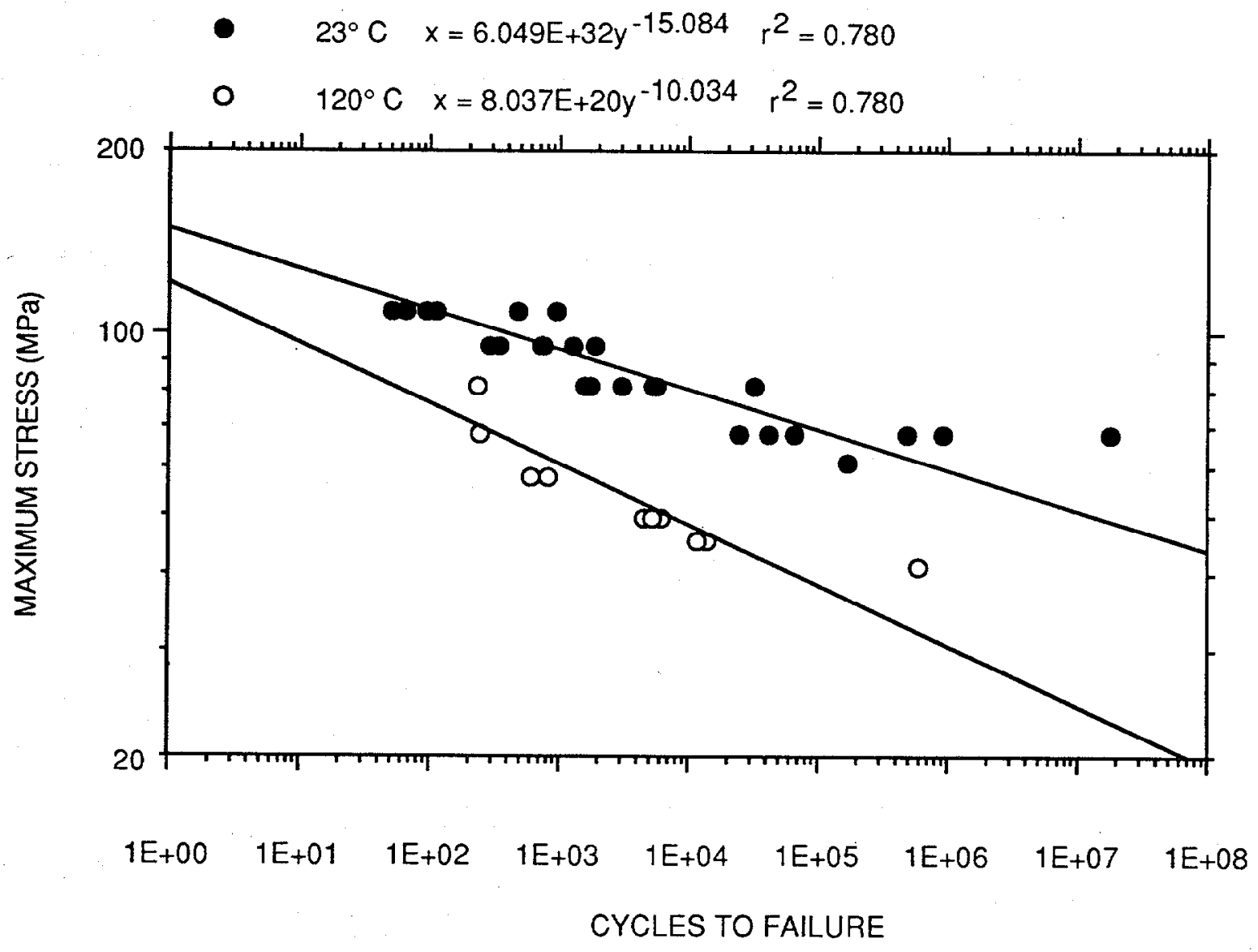

Fig. 4.4. Room-temperature and $120^{\circ} \mathrm{C}$ fatigue curves for specimens with $\pm 45^{\circ}$ fiber orientation. 


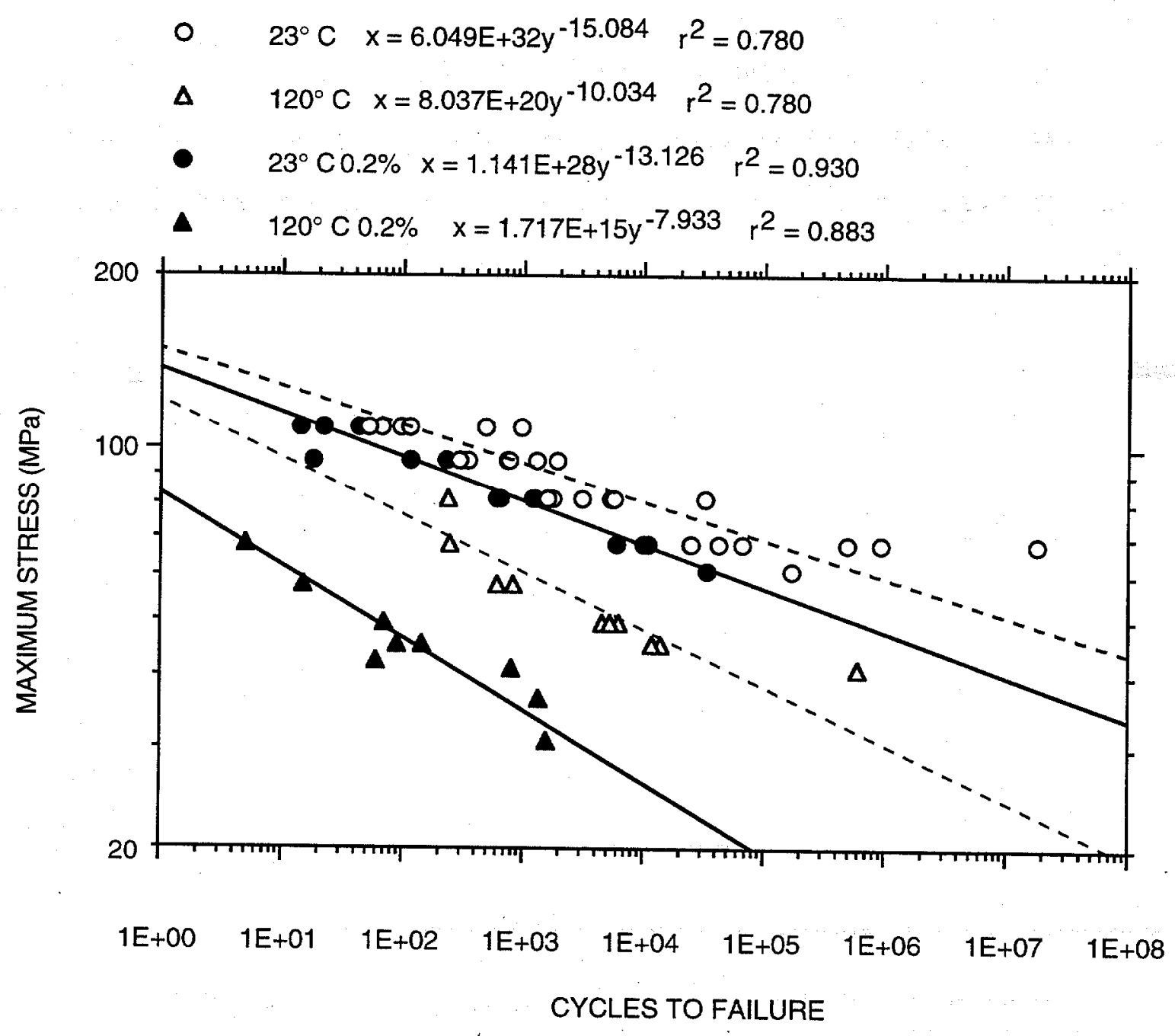

Fig. 4.5. Fatigue curves for $\pm 45^{\circ}$ fiber orientation with failure based on beginning of rapid increase of maximum strain (solid lines and symbols). Curves from Fig. 4.3 are shown as open symbols and dashed lines. 


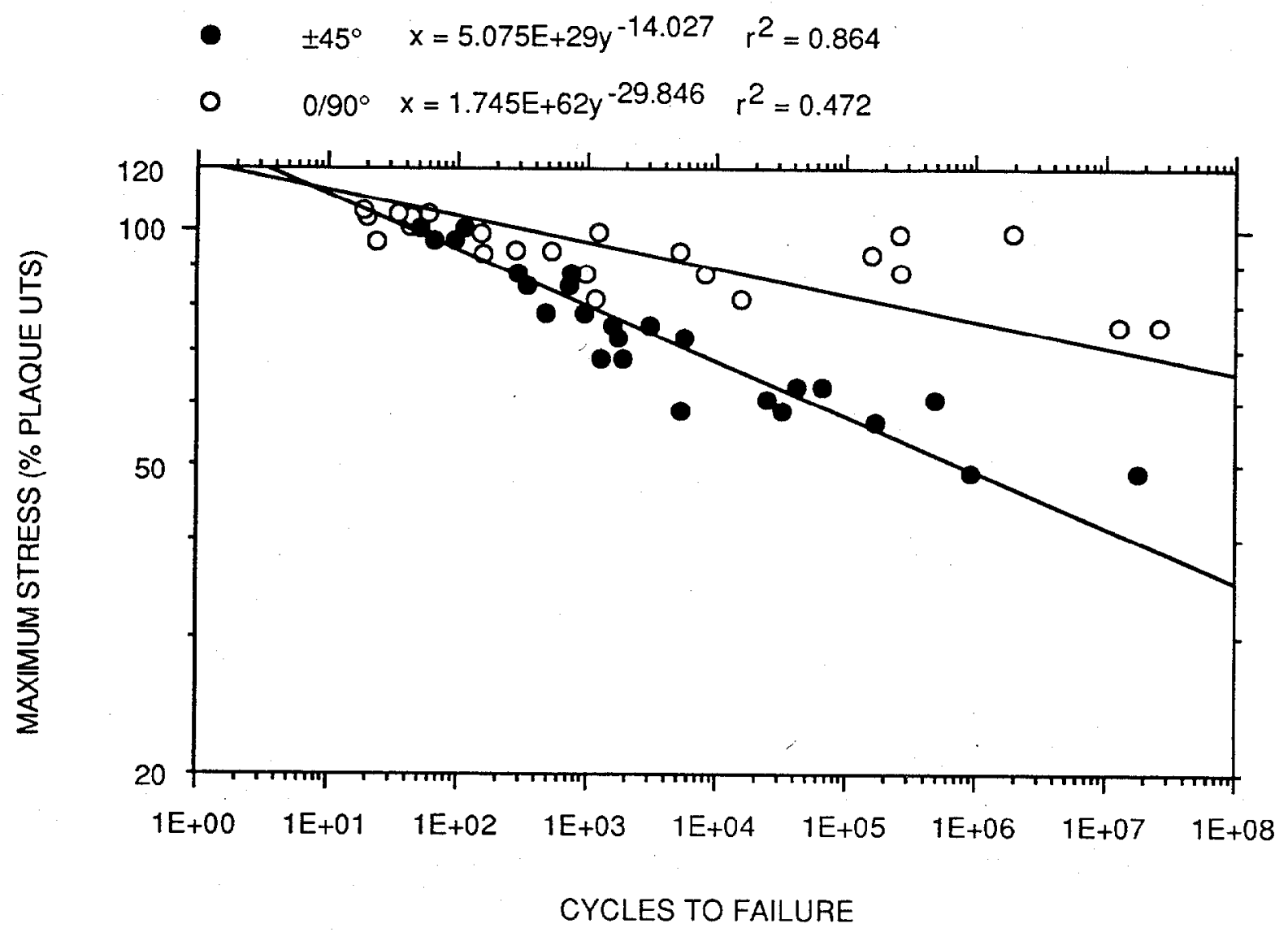

Fig. 4.6. Room-temperature fatigue curves with stress expressed as percent of the plaque average UTS values. 


\section{TENSILE CREEP BEHAVIOR}

A preliminary series of exploratory tensile creep tests has been performed at room temperature on both specimens having the $0 / 90^{\circ}$ fiber orientation and specimens with the $\pm 45^{\circ}$ fiber orientation. Standard dogbone tensile specimens, described in Ref. 1, were used in both cases. Because these tests were exploratory, several needed improvements in the test method, and adjustments to the test parameters were identified and have been incorporated into a second series of tests that is now under way. Nonetheless, the preliminary series of tests was sufficient for the development of interim time-dependent creep strain vs time equations and for a first look at creep-rupture behavior. The results are presented in this chapter.

\subsection{SPECIMENS AND TEST PROCEDURE}

All specimens having the $0 / 90^{\circ}$ fiber orientation were fabricated from plaque $\mathrm{C} 2$, and those having the $\pm 45^{\circ}$ orientation were fabricated from plaque $\mathrm{C} 6$. From Tables 3.1 and $3.2, \mathrm{C} 2$ appears to be a stronger than average plaque, while $\mathrm{C} 6$ is weaker than average. The cross-sectional thicknesses of the specimens are tabulated in Table 5.1, which lists the creep test parameters and key results.

Creep strain was measured using a single strain gage (one side only) per specimen. Recall that the reinforcement was unsymmetric in plaques $\mathrm{C} 2$ and $\mathrm{C} 6$. For $0 / 90^{\circ}$ specimens, the single gage was generally placed on the surface where the first fiber layer, or ply, was in the $0^{\circ}$ direction. Thus, the gage and the closest fibers to the surface were parallel. However, in a few cases the single gage was placed on the surface where the first fiber layer was at $90^{\circ}$. This may have had some effect on the indicated strain.

An attempt was made to load every specimen at a constant strain rate of $0.04 / \mathrm{min}$, but this was not always closely achieved due to the inherent limitations of the mechanical load clcvator used to lower the deadweights on to the load pans of the lever-arm creep machines. This problem has been rectified in the second series of tests currently under way. An electrohydraulic feedback controlled elevator is now being used. All tests were performed at room temperature in air having a nominal relative humidity of $50 \%$.

\subsection{CREEP DEFORMATION}

\subsubsection{0/90 ${ }^{\circ}$ Fiber Orientation}

As indicated in Table 5.1, 13 creep tests were successfully completed on $0 / 90^{\circ}$ specimens. Four of these ended in creep rupture; the remainder were terminated after several thousand hours of testing.

Representative time-dependent creep strain results are plotted in Figs. 5.1 and 5.2, separated according to the specimens' number, and thus location, in plaque $\mathrm{C} 2$. Figure 5.1 has results from specimens numbered $\mathrm{C} 16$ and below, while Fig. 5.2 contains results for specimens numbered $\mathrm{C} 30$ and above. The latter specimens are from the generally thicker portion of the plaque and are thus subjected to somewhat higher loads than the thinner specimens in Fig. 5.1 (to yield the same stress levels). The group in Fig. 5.2 would be expected to creep somewhat more than that in Fig. 5.1 because the same number of fibers is carrying a higher load. There is, however, little apparent difference in the two sets of data.

Note that curves for three of the tests in Table 5.1 were not plotted in Fig. 5.1. Specimens C2-7 (400 MPa), C2-13 (450 MPa), and C2-16 (470 MPa) were not used because strains from these tests seemed to be clearly out of line with the other results in Figs. 5.1 and 5.2.

The creep strains in Figs. 5.1 and 5.2 are extremely small. Once past the primary creep stage, the strains are not much larger than the strain gage resolution. Laboratory temperature and humidity swings 
can significantly contribute to data scatter in this range. In spite of this, the essential creep behavior is well portrayed, and the consistency of the data permits a simple creep equation to be developed.

Table 5.1. Summary of test parameters and results of creep tests on carbon-fiber composite specimens in the $0 / 90^{\circ}$ and $\pm 45^{\circ}$ orientations

\begin{tabular}{|c|c|c|c|c|c|c|c|}
\hline $\begin{array}{c}\text { Specimen } \\
\text { No. } \\
\end{array}$ & $\begin{array}{l}\text { Stress } \\
(\mathrm{MPa}) \\
\end{array}$ & $\begin{array}{c}\text { Thickness } \\
\text { (mm) }\end{array}$ & $\begin{array}{c}\text { Loading } \\
\text { strain (\%) }\end{array}$ & $\begin{array}{c}\text { Creep } \\
\text { strain }(\%)\end{array}$ & $\begin{array}{c}\text { Time } \\
\text { tested }(\mathrm{h})\end{array}$ & $\begin{array}{l}\text { Rupture } \\
\text { life (h) }\end{array}$ & Notes \\
\hline \multicolumn{8}{|c|}{$0 / 90^{\circ}$ Fiber orientation } \\
\hline $\mathrm{C} 2-5$ & 100 & 3.157 & 0.2 & 0.0247 & 6290 & & Test discontinued \\
\hline $\mathrm{C} 2-31$ & 100 & 3.180 & 0.19 & 0.025 & 5636 & & Test discontinued \\
\hline $\mathrm{C} 2-30$ & 200 & 3.152 & 0.38 & 0.0383 & 5763 & & Test discontinued \\
\hline $\mathrm{C} 2-33$ & 200 & 3.249 & 0.419 & 0.0226 & 5621 & & Test discontinued \\
\hline $\mathrm{C} 2-15$ & 300 & 3.101 & 0.56 & 0.0677 & 6248 & & Test discontinued \\
\hline $\mathrm{C} 2-34$ & 300 & 3.265 & 0.61 & 0.065 & 5617 & & Test discontinued \\
\hline $\mathrm{C} 2-6$ & 400 & 3.173 & 0.78 & 0.1 & & 7.74 & Failed \\
\hline $\mathrm{C} 2-7$ & 400 & 3.18 & 0.786 & 0.0681 & 8835 & & Test discontinued \\
\hline $\mathrm{C} 2-8$ & 400 & 3.197 & 0.825 & 0.093 & & 4641 & Failed \\
\hline $\mathrm{C} 2-35$ & 400 & 3.302 & 0.787 & 0.0862 & 5214 & & Test discontinued \\
\hline $\mathrm{C} 2-13$ & 450 & 3.048 & 0.8 & 0.11 & 6914 & & Test discontinued \\
\hline $\mathrm{C} 2-14$ & 450 & 3.073 & 0.86 & 0.067 & & 87.01 & Failed \\
\hline $\mathrm{C} 2-16$ & 470 & 3.124 & 0.83 & 0.07 & & 2597.5 & Failed \\
\hline \multicolumn{8}{|c|}{ $\pm 45^{\circ}$ Fiber orientation } \\
\hline C6-9 & 25 & 3.302 & 0.208 & 0.1079 & 5718 & & Test discontinued \\
\hline C6-28 & 25 & 3.556 & 0.227 & 0.1153 & 3173 & & Test discontinued \\
\hline $\mathrm{C} 6-48$ & 25 & 3.962 & 0.25 & 0.2332 & 4855 & & Test discontinued \\
\hline C6-8 & 50 & 3.277 & 0.42 & 0.4717 & 2712 & & Test discontinued \\
\hline $\mathrm{C} 6-38$ & 50 & 3.708 & 0.46 & 0.67 & 5810 & & Test discontinued \\
\hline C6-7 & 75 & 3.251 & 0.67 & 1.95 & 4905 & & Test discontinued \\
\hline C6-39 & 75 & 3.759 & 0.913 & 2.015 & 5791 & & Test discontinued \\
\hline C6-5 & 100 & 3.20 & 1.41 & $>4.7$ & 6241 & & Test discontinued \\
\hline C6-27 & 100 & 3.531 & & & & 146.4 & Rupture test only ${ }^{\mathrm{a}}$ \\
\hline C6-40 & 100 & 3.81 & 1.53 & 2.78 & & 4.61 & Failed \\
\hline C6-41 & 100 & 3.81 & 1.62 & 4.54 & & 20.2 & Failed \\
\hline C6-25 & 103 & 3.531 & & & & 27.1 & Rupture test only ${ }^{a}$ \\
\hline C6-24 & 107 & 3.505 & & & & 0.22 & Rupture test only ${ }^{\mathrm{a}}$ \\
\hline
\end{tabular}

${ }^{\mathrm{a}}$ No strain measurement.

Examination of the experimental curves in Figs. 5.1 and 5.2 indicates that the creep behavior beyond $1000 \mathrm{~h}$ is approximately a linear function of applied stress. This observation suggests that the behavior can be reasonably well represented by an interim creep equation of the usual power law form

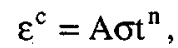


where $\varepsilon^{c}$ is the time-dependent creep strain in percent, $\sigma$ is the applied stress in megapascals, $t$ is time in hours, and $A$ and $n$ are constants. The explicit form of Eq. (5.1) shown below was derived to best fit the creep curves for stresses of $400 \mathrm{MPa}$ and below

$$
\varepsilon^{c}=0.8303 \times 10^{-4} \sigma t^{0.112}
$$

Curves predicted by Eq. (5.2) are plotted with the experimental curves in Figs. 5.1 and 5.2. Agreement between predictions and experimental data are respectable in view of the small creep strains exhibited. The equation tends to overpredict the primary creep regime in the low-stress range and underpredict that in the higher stress range. It appears that the linearity assumption is not valid above a stress threshold of about $400 \mathrm{MPa}$.

\subsection{2 $\pm 45^{\circ}$ Fiber Orientation}

Table 5.1 lists results for 13 creep tests for $\pm 45^{\circ}$ specimens. Of these, three were rupture-only tests where strain was not measured. Time-dependent creep strain vs time curves from the remaining ten tests are plotted in Fig. 5.3. The creep deformation exhibited by the $\pm 45^{\circ}$ specimens is much higher than that for the $0 / 90^{\circ}$ specimens, despite the fact that the applied stresses are significantly lower. For example, the creep strain in $\pm 45^{\circ}$ specimens subjected to an applied stress of $100 \mathrm{MPa}$ quickly exceeded $4 \%$, whereas at the same stress level the creep strain in $0 / 90^{\circ}$ specimens required several thousand hours to reach $0.02 \%$. In-plane and interlaminar shear cracking in the $\pm 45^{\circ}$ specimens is responsible for the large strains, just as it was in the case of short-time tension and cyclic fatigue tests. The 100-MPa test result with the arrow (indicating a continuing test) had a hairline crack under the strain gage, causing the gage to fail at the point shown. The test actually continued to $6241 \mathrm{~h}$, where it was discontinued.

Probably because of the cracking and associated deformations, the creep strains are not linear with stress, as they were in the $0 / 90^{\circ}$ case. However, the strains can be represented by an interim creep equation of the form

$$
\varepsilon^{\mathrm{c}}=\mathrm{A} \sigma^{\mathrm{m}} \mathrm{t}^{\mathrm{n}}
$$

where $\mathrm{m}$ is an added constant. The explicit form of Eq. (5.3) shown below was derived to fit the curves for $75 \mathrm{MPa}$ and below.

$$
\varepsilon^{\mathrm{c}}=4.074 \times 10^{-6} \sigma^{2.634} t^{0.20}
$$

The predictions of this equation are compared with the experimental data in Fig. 5.3. The agreement is very good except at $100 \mathrm{MPa}$, indicating there is a threshold between 75 and $100 \mathrm{MPa}$.

To examine the effects of thickness in the $\pm 45^{\circ}$ specimens, the three 25 -MPa curves are replotted in Fig. 5.4 using an expanded scale. Here the thickest specimen (C6-48) was subjected to the largest load because its area was largest, and it showed the most creep. The thinnest specimen (C6-9) had the lowest load and showed the least amount of creep. The stress values in Fig. 5.4 are based on all of the specimen thicknesses being the same and equal to that of C6-9. The predicted curves were based on these adjusted stress levels. While the curves are qualitatively similar, the quantitative agreement is not good. This indicates that the simple area concept cannot, by itself, account for the complex shear deformations in the matrix material. 


\subsection{CREEP RUPTURE}

Only a total of nine tests reached creep rupture-four for the $0 / 90^{\circ}$ specimens and five for the $\pm 45^{\circ}$ specimens. These data are plotted in Fig. 5.5, where stress is shown vs rupture time. In the case of the four $0 / 90^{\circ}$ specimens, the results show no apparent downward trend of rupture stress with time. In contrast, there does appear to be a slight drop in stress with time in the case of the $\pm 45^{\circ}$ specimens, and it was possible to develop an interim creep-rupture correlation.

While the creep-rupture strength is high for the $0 / 90^{\circ}$ fiber orientation, the $\pm 45^{\circ}$ strength is slightly lower than that of either of the random-glass-fiber composites previously tested. Note that the $\pm 45^{\circ}$ points plotted in Fig. 5.5 represent complete specimen separation, which occurs only after large deformations are induced by shear failures. If a more realistic definition of "failure" were adopted, the $\pm 45^{\circ}$ curves would drop even lower. 


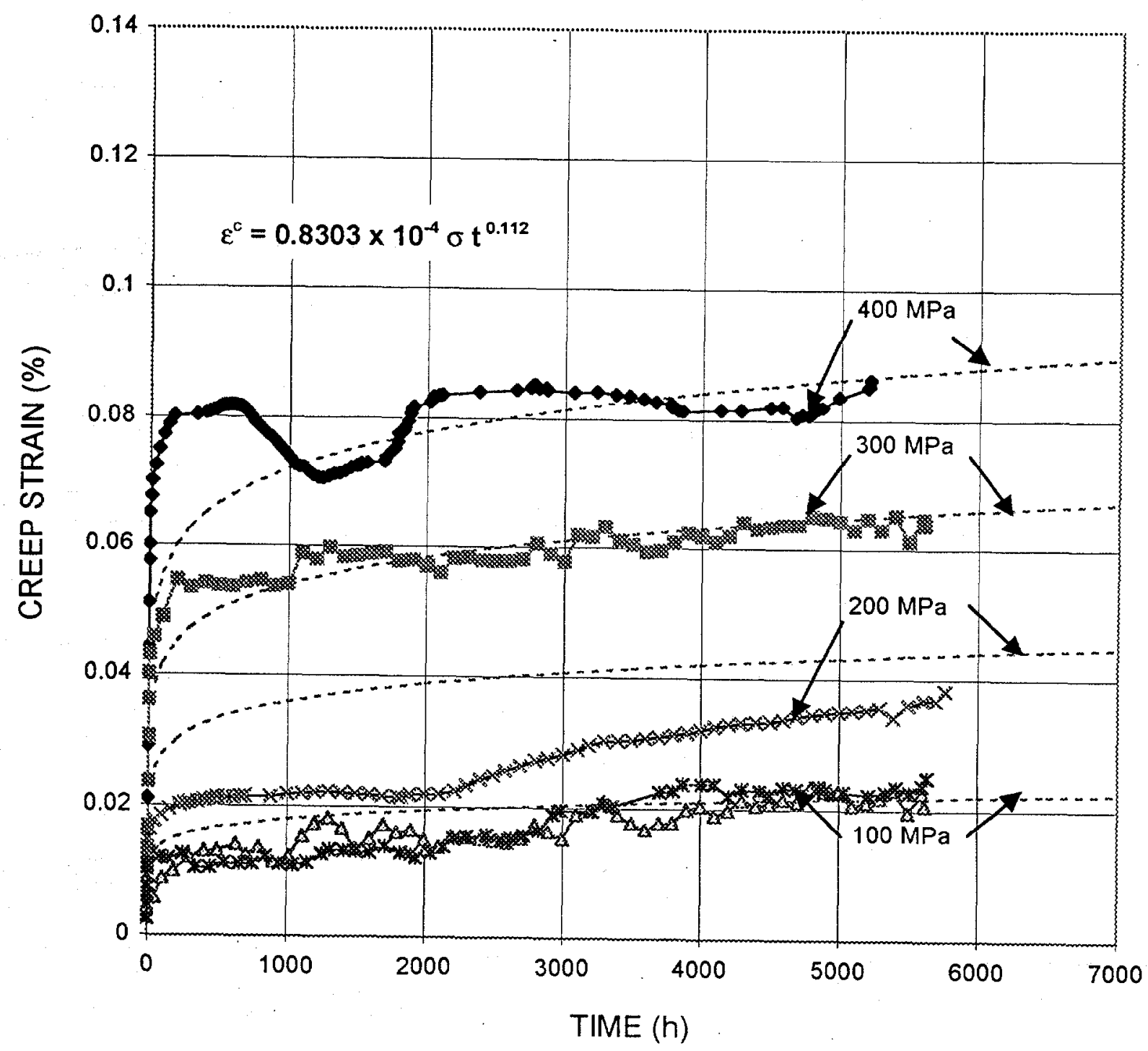

Fig. 5.1. Experimental time-dependent creep strain vs time curves for Group A (generally thinner) $0 / 90^{\circ}$ specimens compared with predictions of (Eq. 5.2). 


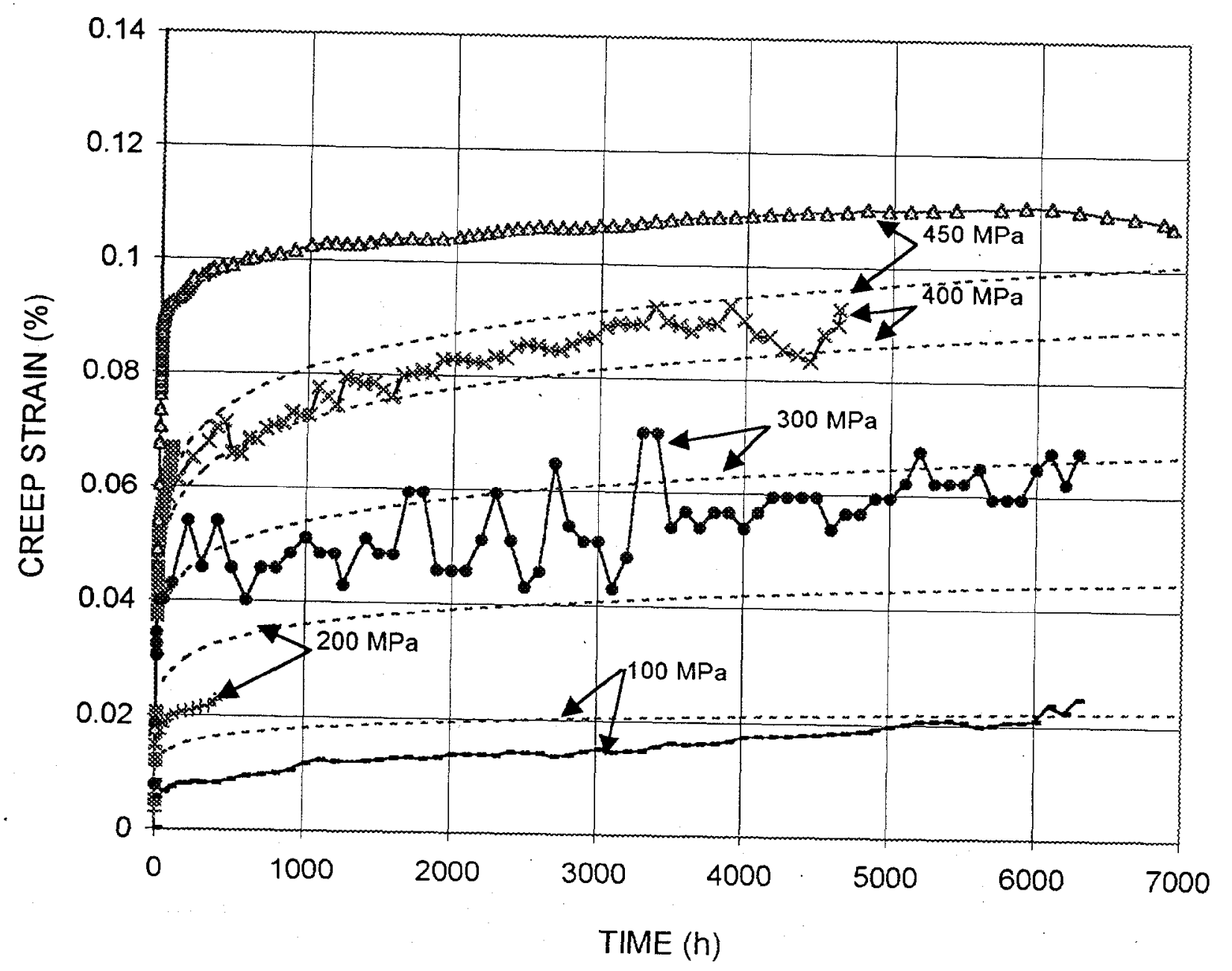

Fig. 5.2. Experimental time-dependent creep strain vs time curves for Group B (generally thicker) $0 / 90^{\circ}$ specimens compared with predictions of (Eq. 5.2). 


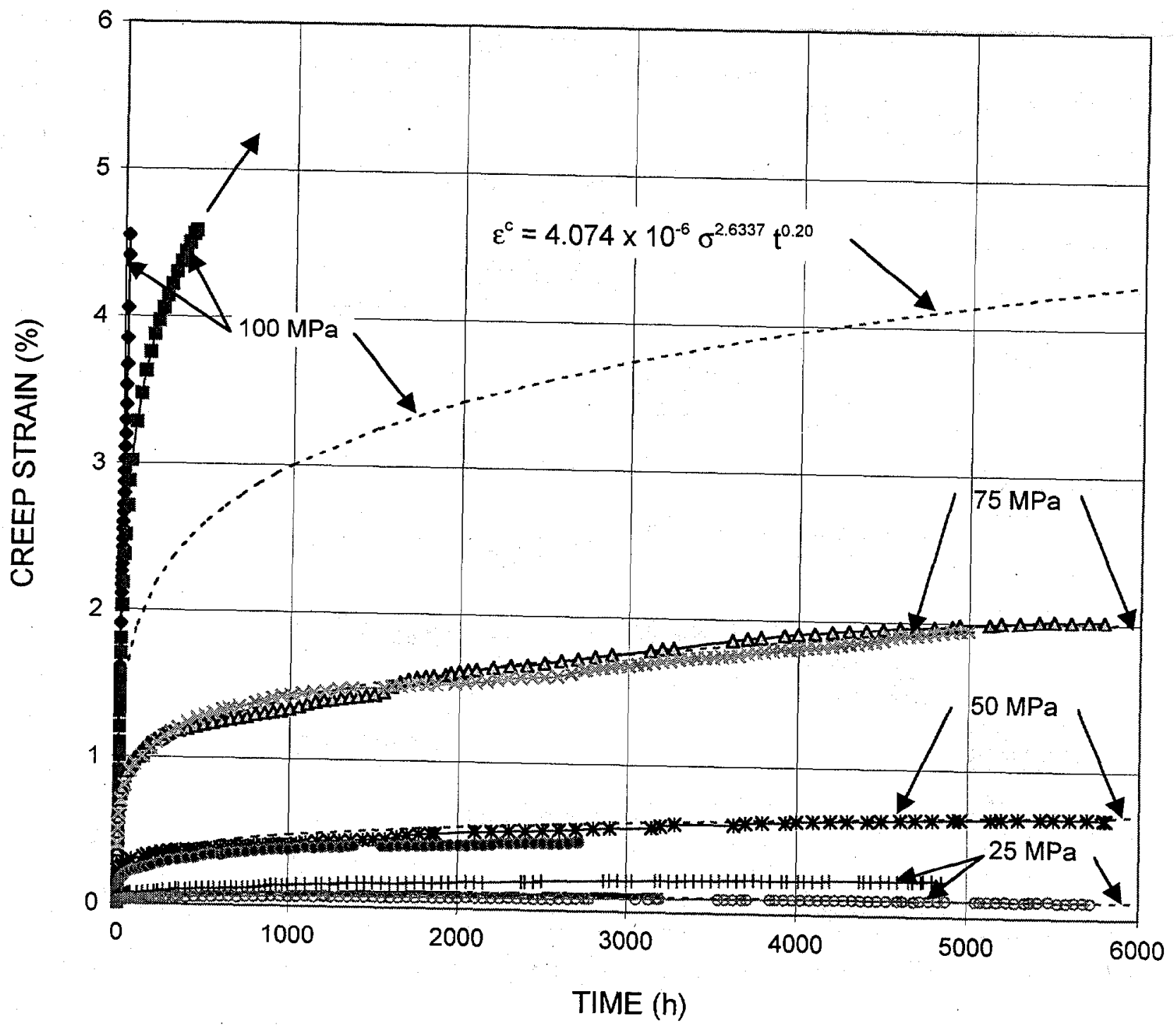

Fig. 5.3. Experimental time-dependent creep strain vs time curves for $\pm 45^{\circ}$ specimens compared with predictions of (Eq. 5.4). 


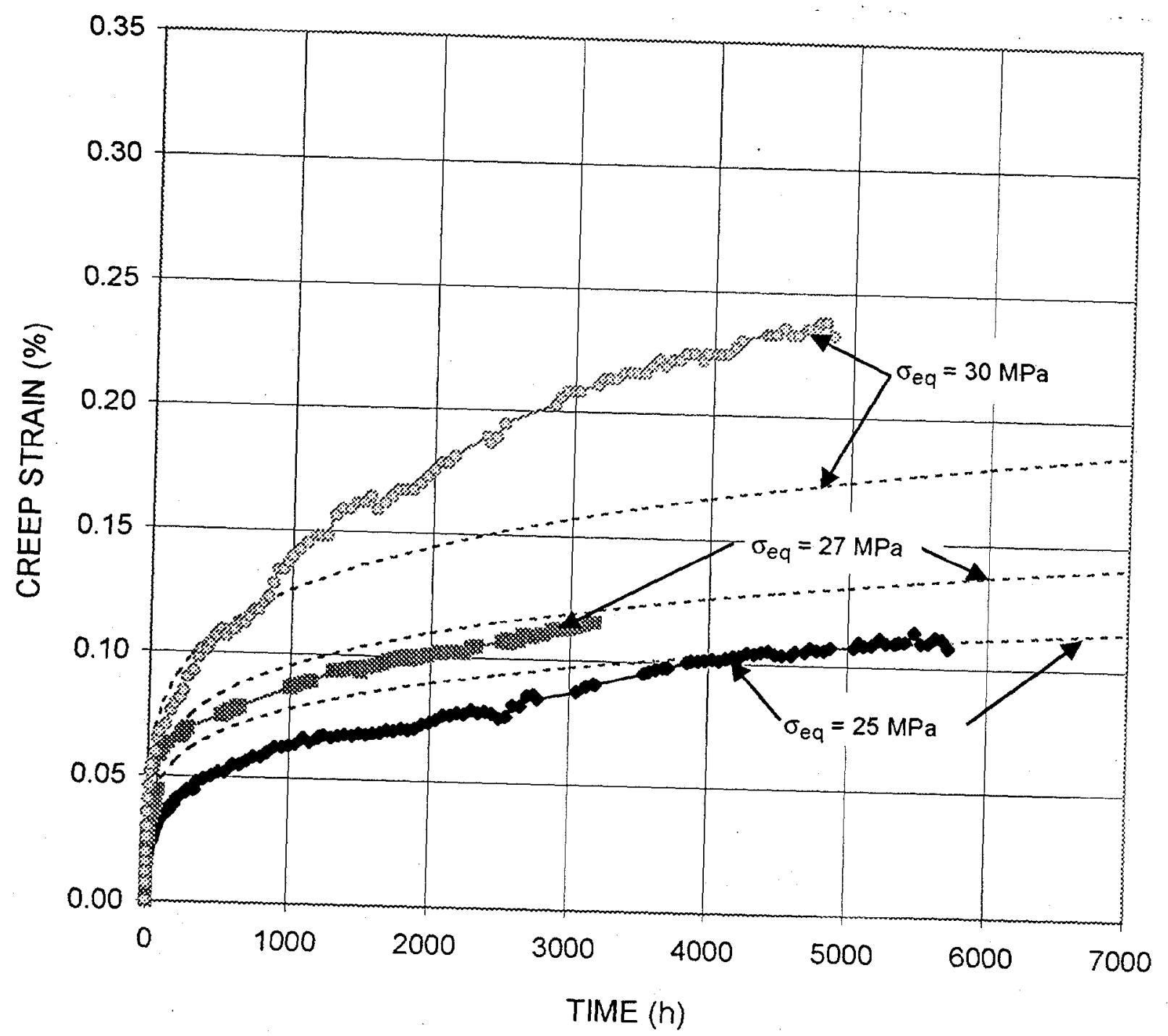

Fig. 5.4. Detailed look at three 25-MPa creep curves from Fig. 5.3 using equivalent stresses based on thickness-based adjustment. 


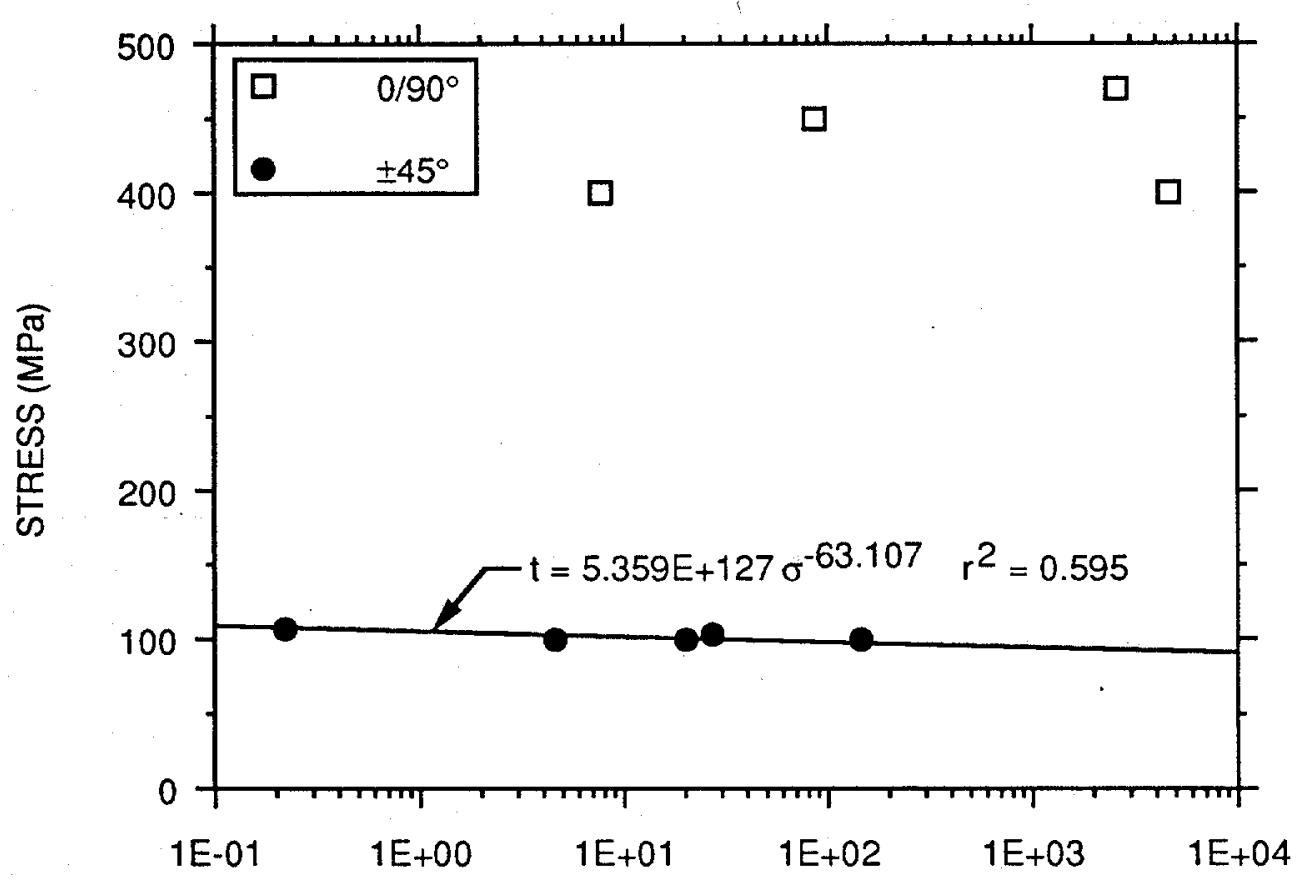

RUPTURE TIME (h)

Fig. 5.5. Creep-rupture data for specimens with $0 / 90^{\circ}$ and $\pm 45^{\circ}$ fiber orientations. 


\section{REFERENCES}

1. J. M. Corum, R. L. Battiste, W. Ren, and M. B. Ruggles, Recommended Minimum Test Requirements and Test Methods for Assessing Durability of Random-Glass-Fiber Composites, ORNL-6953, Lockheed Martin Energy Research Corp., Oak Ridge National Laboratory, June 1999.

2. J. Gao and Y. J. Weitsman, The Tensile Mechanical Properties and Failure Behavior of Stitched T300 Mat/Urethane 420 IMR Composite, MAE598-2.0-CM, The University of Tennessee, July 1998.

3. J. M. Corum et al., Durability-Based Design Criteria for an Automotive Structural Composites: Part 2. Background Data and Models, ORNL-6931, Lockheed Martin Energy Research Corp., Oak Ridge National Laboratory, February 1998.

4. J. M. Corum, R. L. Battiste, W. Ren, and M. B. Ruggles, Durability-Based Design Criteria for a Chopped-Glass-Fiber Automotive Structural Composite, ORNL-TM-1999/182, Lockheed Martin Energy Research Corp., Oak Ridge National Laboratory, November 1999.

5. R. Talreja, "Fatigue of Composite Materials," in Durability of Polymer Matrix Composites for Automotive Structural Applications: A State-of-the-Art Review, ORNL-6869, Martin Marietta Energy Systems, Inc., Oak Ridge National Laboratory, July 1995. 


\section{Appendix A}

\section{DETERMINATION OF TEMPERATURE DEPENDENCE OF TENSILE, COMPRESSIVE, AND SHEAR PROPERTIES}

For the $0 / 90^{\circ}$ fiber orientation, the effects of temperature on tensile and compressive properties were investigated in 33 tensile tests $\left(6\right.$ tests at $-40^{\circ} \mathrm{C}$ and 9 tests at each of the other temperatures) on specimens from plaques $\mathrm{C} 1$ and $\mathrm{C} 5$ and 36 compressive tests (12 tests at room temperature and 8 tests at each of the other temperatures) on specimens from plaques $\mathrm{C} 2-\mathrm{C} 5$, conducted at $-40,23,50$ and $120^{\circ} \mathrm{C}$. The effects of temperature on shear properties were assessed in 33 shear tests ( 15 tests at room temperature and 6 tests at each of the other temperatures) on specimens from plaques $\mathrm{C} 1-\mathrm{C} 3$ conducted at $-40,23,70$, and $120^{\circ} \mathrm{C}$.

For the $\pm 45^{\circ}$ fiber orientation, the effects of temperature on tensile and compressive properties were investigated in 30 tensile tests $\left(12\right.$ tests at $70^{\circ} \mathrm{C}$ and 6 tests at each of the other temperatures) on specimens from plaque $\mathrm{C} 11$ and 24 compressive tests ( 6 tests at each temperature) on specimens from plaque $\mathrm{C} 26$, conducted at $-40,23,70$, and $120^{\circ} \mathrm{C}$. The effects of temperature on shear properties were investigated in 24 tests ( 6 tests at each temperature) conducted at $-40,23$, and $70^{\circ}$, and $120^{\circ} \mathrm{C}$ on specimens from plaque $\mathrm{C} 21$.

The average properties produced in the tests described above are presented in Tables A.1 and A.2 for the $0 / 90^{\circ}$ and $\pm 45^{\circ}$ orientations, respectively. Given in parentheses are the corresponding percent coefficients of variation. For each property, percent changes from room-temperature values were calculated and plotted vs temperature. Then, a correlation between percent change in property and temperature was developed. These correlations were specifically formulated to give $0 \%$ change at room temperature. Based on these correlations, properties at different temperatures and corresponding multiplication factors were calculated. Correlations between the multiplication factors and temperature were developed, so multiplication factors for any temperature within range can be established. Finally, these factors were applied to the baseline room-temperature properties to obtain the at-temperature properties tabulated in Sect. 3.4. 
Table A.1. Average properties from temperature dependence study for $0 / 90^{\circ}$ fiber orientation

\begin{tabular}{cccccc}
\hline \multirow{2}{*}{ Property } & \multicolumn{5}{c}{ Temperature $\left({ }^{\circ} \mathrm{C}\right)$} \\
\cline { 2 - 5 } & -40 & 23 & 50 & 70 & 120 \\
\hline Tension & & & & 39.8 \\
Modulus, GPa & 44.7 & 44.5 & 45.0 & $(6.82)$ \\
& $(3.98)$ & $(6.51)^{\mathrm{a}}$ & $(5.07)$ & 418 \\
Strength, MPa & 508 & 516 & 503 & $(8.37)$ \\
& $(6.88)$ & $(9.50)$ & $(3.01)$ & \\
Compression & & & & 40.0 \\
Modulus, GPa & 51.8 & 50.4 & 46.5 & $(8.47)$ \\
Strength, MPa & $(2.09)$ & $(8.92)$ & $(8.08)$ & & 190 \\
& 496 & 478 & 381 & & $(13.0)$ \\
Shear & $(3.93)$ & $(6.99)$ & $(6.03)$ & & \\
Modulus, GPa & & & & & \\
& & & & 2.11 & 0.60 \\
Strength, MPa & 3.31 & 2.96 & & $(6.72)$ & $(5.20)$ \\
& $(3.93)$ & $(11.2)$ & & $(4.15)$ & $(7.52)$ \\
\hline
\end{tabular}

${ }^{\mathrm{a}}$ Numbers in parentheses are percent coefficients of variation.

Table A.2. Average properties from temperature dependence study for $\pm 45^{\circ}$ fiber orientation

\begin{tabular}{ccccc}
\hline \multirow{2}{*}{ Property } & \multicolumn{4}{c}{ Temperature $\left({ }^{\circ} \mathrm{C}\right)$} \\
\cline { 2 - 5 } & -40 & 23 & 70 & 120 \\
\hline Tension & & & \\
Modulus, GPa & 13.3 & 10.1 & 8.95 & 3.98 \\
& $(7.64)$ & $(5.49)$ & $(6.99)$ & $(6.41)$ \\
Strength, MPa & 160 & 126 & 105 & 75.5 \\
& $(3.21)$ & $(4.56)$ & $(3.49)$ & $(6.18)$ \\
Compression & & & & \\
Modulus, GPa & 17.3 & 13.9 & 108 & 6.24 \\
& $(3.75)$ & $(7.08)$ & $(6.47)$ & $(7.06)$ \\
Strength, MPa & 215 & 163 & 121 & 78.1 \\
& $(3.23)$ & $(4.59)$ & $(7.12)$ & $(1.88)$ \\
Shear & & & & \\
Modulus, GPa & & & & \\
Strength, MPa & 30.2 & 24.2 & 18.5 & 14.4 \\
& $(7.27)$ & $(2.65)$ & $(3.38)$ & $(10.0)$ \\
& 248 & 191 & 111 & 84.3 \\
& $(7.30)$ & $(9.80)$ & $(8.42)$ & $(8.51)$ \\
\hline
\end{tabular}

${ }^{\mathrm{a}}$ Numbers in parentheses are percent coefficients of variation. 


\section{Appendix B}

\section{DAMAGE ACCUMULATION IN TENSILE FATIGUE TESTS}

Damage in tensile fatigue tests is normally manifest as a decrease in stiffness with increasing cycle number. The maximum cyclic strain also increases with cycling. To explore this behavior in specimens with $0 / 90^{\circ}$ and $\pm 45^{\circ}$ fiber orientations, axial strains were monitored in selected tests of specimens with each orientation at room temperature and $120^{\circ} \mathrm{C}$. Plots of stiffness reduction and maximum strain are presented in this appendix for each temperature/fiber orientation combination.

\section{B.1. 0/90 ${ }^{\circ}$ FIBER ORIENTATION}

Figures B.1 and B.2 show the room-temperature stiffness reduction and maximum strain behavior, respectively, for six $0 / 90^{\circ}$ specimens from a single plaque, C15. The abscissa of Fig. B.1 is life fraction (cycle number divided by number of cycles to failure), while in Fig. B.2, it is just cycle number. Figures B.3 and B.4 are similar plots for specimens tested at $120^{\circ} \mathrm{C}$. In the latter case, the specimens came from two plaques, $\mathrm{C} 15$ and $\mathrm{C} 18$.

It is seen from Fig. B.1 that at room temperature the decrease in stiffness is well below 10\%, even at the end of life. At $120^{\circ} \mathrm{C}$, Fig. B. 3 indicates that in the majority of tests the stiffness actually increased over much of the cyclic life. A possible explanation for this is that at the higher temperature the soft matrix allows the fibers to more casily straighten as the test proceeds and become better aligned with the load.

Figure B.2 shows that at room temperature the maximum cyclic strain varies little throughout a cyclic test. At $120^{\circ} \mathrm{C}$ (see Fig. B.4), there is an upward trend, but, except possibly at the highest stress levels, there is not the dramatic increase near the end of life that was observed in the random-glass-fiber composites previously studied and in the carbon-fiber composite when the fibers are oriented at $\pm 45^{\circ}$ (see the following section). This is consistent with the observation in Chap. 4 that fatigue failures in the $0 / 90^{\circ}$ specimens occurred suddenly; there was little forewarning.

\section{B.2. $\pm 45^{\circ}$ FIBER ORIENTATION}

Figures B.5 and B.6 show the stiffness reduction and maximum strain responses, respectively, with cycling of $\pm 45^{\circ}$ specimens at room temperature. Figures B.7 and B.8 show the variation of the same quantities at $120^{\circ} \mathrm{C}$. At room temperature, specimens from two plaques, $\mathrm{C} 16$ and $\mathrm{C} 17$, were tested. At $120^{\circ} \mathrm{C}$ only specimens from $\mathrm{C} 17$ were tested. As in the previous figures, the numbers in parentheses in the lcgends indicate the maximum cyclic stress used in each test as a percentage of the average at-lemperature UTS.

While the end-of-life stiffness reductions shown for room temperature tests in Fig. B.5 are considerably larger than those observed for the random-glass-fiber composites, the curves are qualitatively similar. As discussed in Chap. 4, if the number of cycles corresponding to a $10 \%$ stiffness reduction is used as a criterion for failure, a well-defined S-N curve is obtained. This is not the case at $120^{\circ} \mathrm{C}$. Figure B.7 indicates that in all but the lowest stress cases, the stiffness dropped $10 \%$ in just a few cycles. At the two lowest stresses, stiffness actually increased. Thus, some criterion other than stiffncss drop is needed.

Figure B.6 shows the maximum strain variations with cycling at room temperature. These curves were arbitrarily terminated at a strain of $5 \%$. The line labeled "rapid damage line" was drawn to represent the approximate transition from a slow, nearly linear, growth region to a rapidly increasing damage growth 
region. In the latter region, in-plane and interlaminar shearing (scissoring) result in large specimen deformations. Thus, the transition represents functional failure.

To quantify the threshold in a consistent way in each case, a $0.2 \%$ offset method was used. As illustrated in Fig. B.9, a straight line, vertically offset by a strain of $0.2 \%$, was drawn parallel to each of the slow damage growth lines. The point at which these lines intersected the corresponding curve determined "failure." ${ }^{\dagger}$ This procedure was used to construct the solid S-N curves shown in Fig. 4.5 at both room temperature and $120^{\circ} \mathrm{C}$.

Figure B.8 shows similar maximum strain curves for $120^{\circ} \mathrm{C}$. As mentioned in Chap. 4 , these specimens did not break into two pieces. Qualitatively, the maximum strain curves are similar to the ones at room temperature, and it was possible to use the $0.2 \%$ strain offset procedure illustrated in Fig. B.9 to determine functional failure.

* The region of slowly increasing maximum strain is probably a reflection of both tensile creep and some microstructural damage.

$\dagger$ The drop in maximum strain observable between the 10 th and 11 th cycles in Fig. B.8, and to a lesser extent in Figs. B.6 and B.4, requires an explanation. The first ten fatigue cycles were continuous in these tests, after which the cycling was stopped and a relatively slow quasi-static stiffness check was performed. The drop in maximum strain occurred when cycling was resumed. This is believed to be a thermo-mechanical effect. It is particularly noticeable in the $\pm 45^{\circ}$ specimens, at $120^{\circ} \mathrm{C}$, and at the higher stresses. In the most extreme conditions, specimens were observed to heat up a few degrees during cycling and to then cool somewhat during the quasi-static check.

In applying the $0.2 \%$ offset procedure, the curves beyond the 10 th cycle were translated upward to eliminate the offset. This was thought to be conservative because it led to a smaller number of cycles than would be determined from the actual curve. 


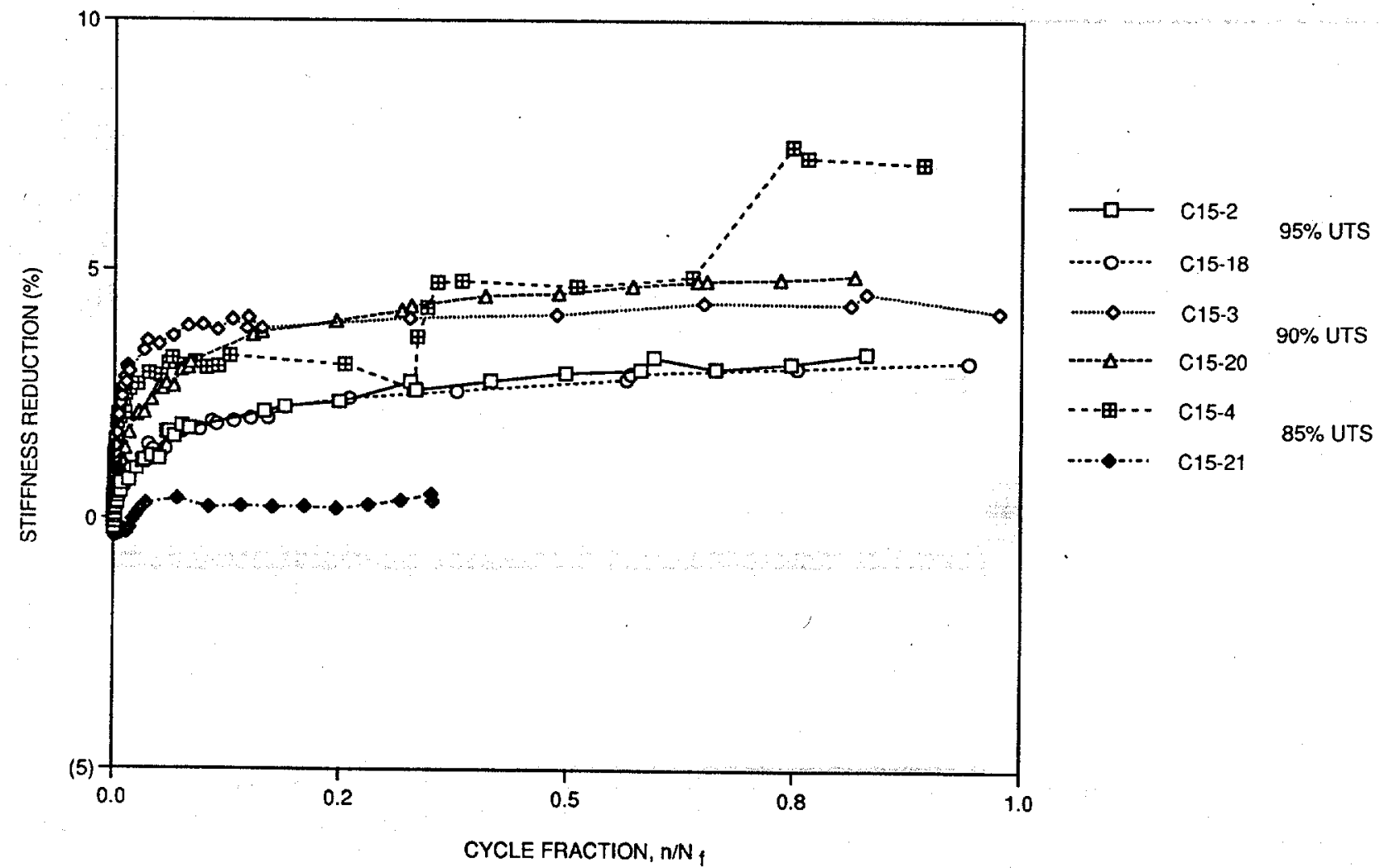

Fig. B.1. Reduction in stiffness with cycling at room temperature for fatigue specimens with $0 / 90^{\circ}$ fiber orientation. As shown in the legend at left, the maximum stress was $95 \%$ of the UTS for two specimens, $90 \%$ for two, and $85 \%$ for two. 


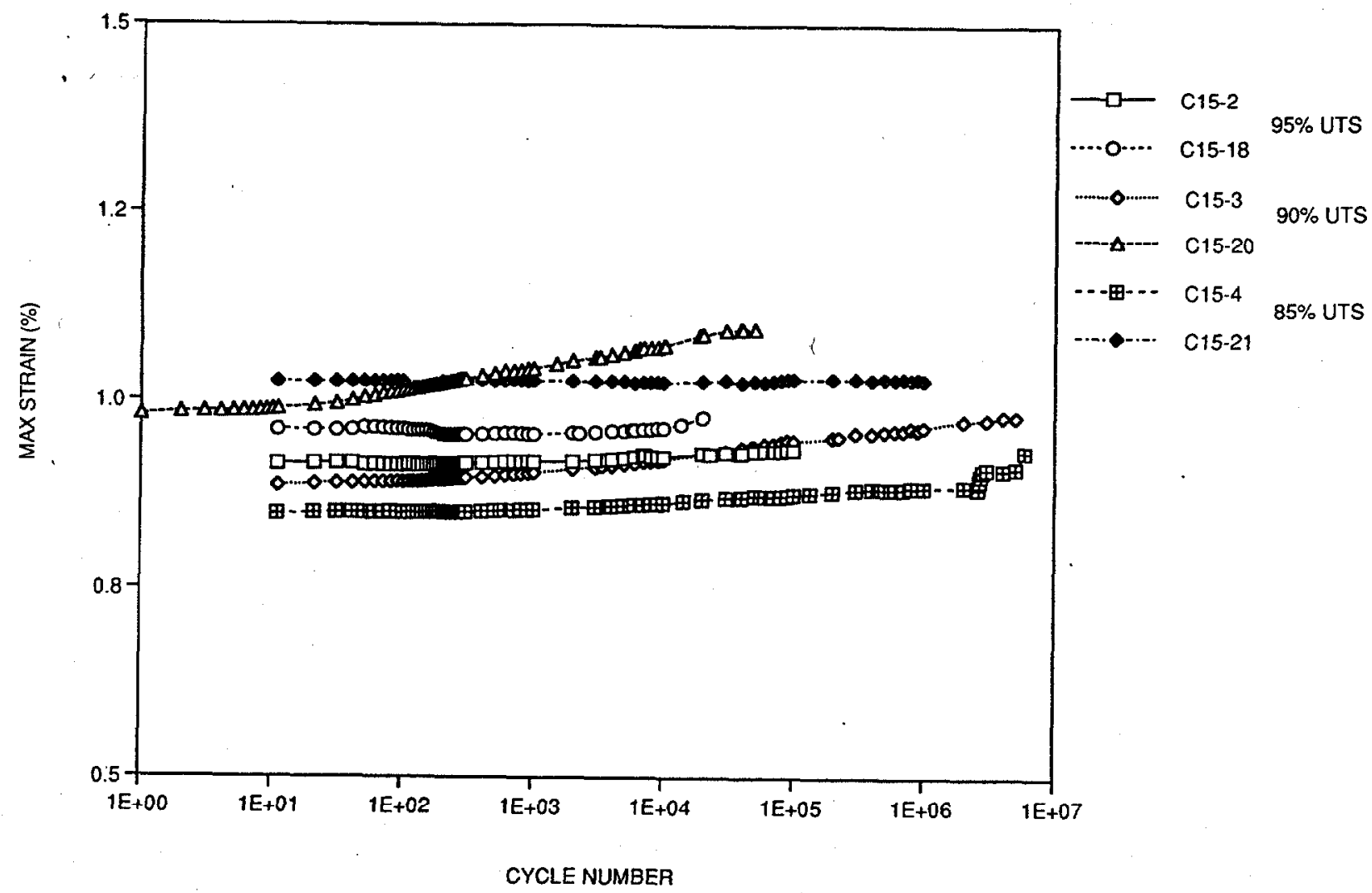

Fig. B.2. Variation of maximum cyclic strain with cycling at room temperature for fatigue specimens with $0 / 90^{\circ}$ fiber orientation. 


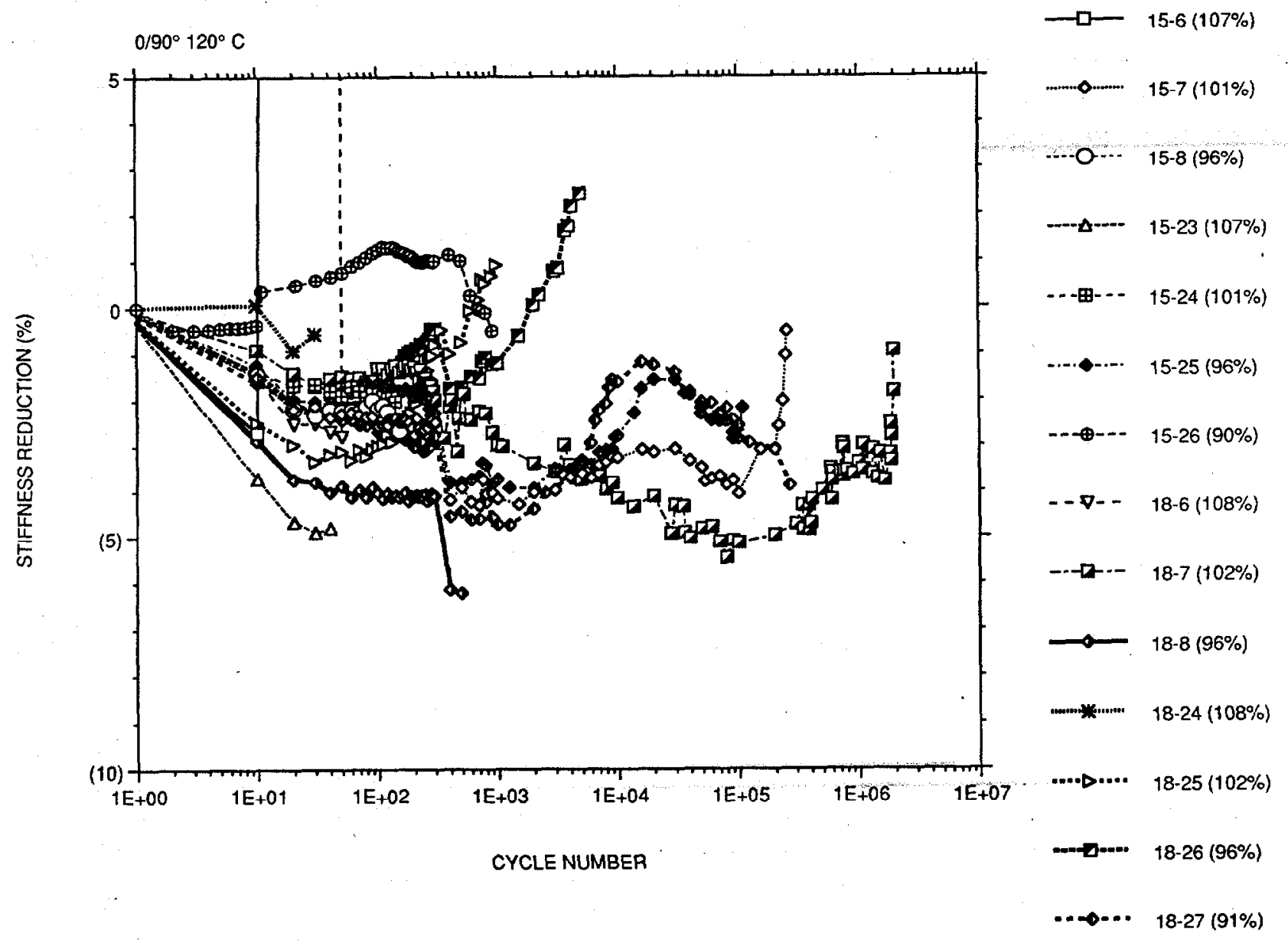

Fig. B.3. Reduction of stiffness with cycling at $120^{\circ} \mathrm{C}$ for fatigue specimens with $0 / 90^{\circ}$ fiber orientation. Numbers in parentheses in the legend indicate the maximum stress as a percentage of the average UTS at $100^{\circ} \mathrm{C}$. 


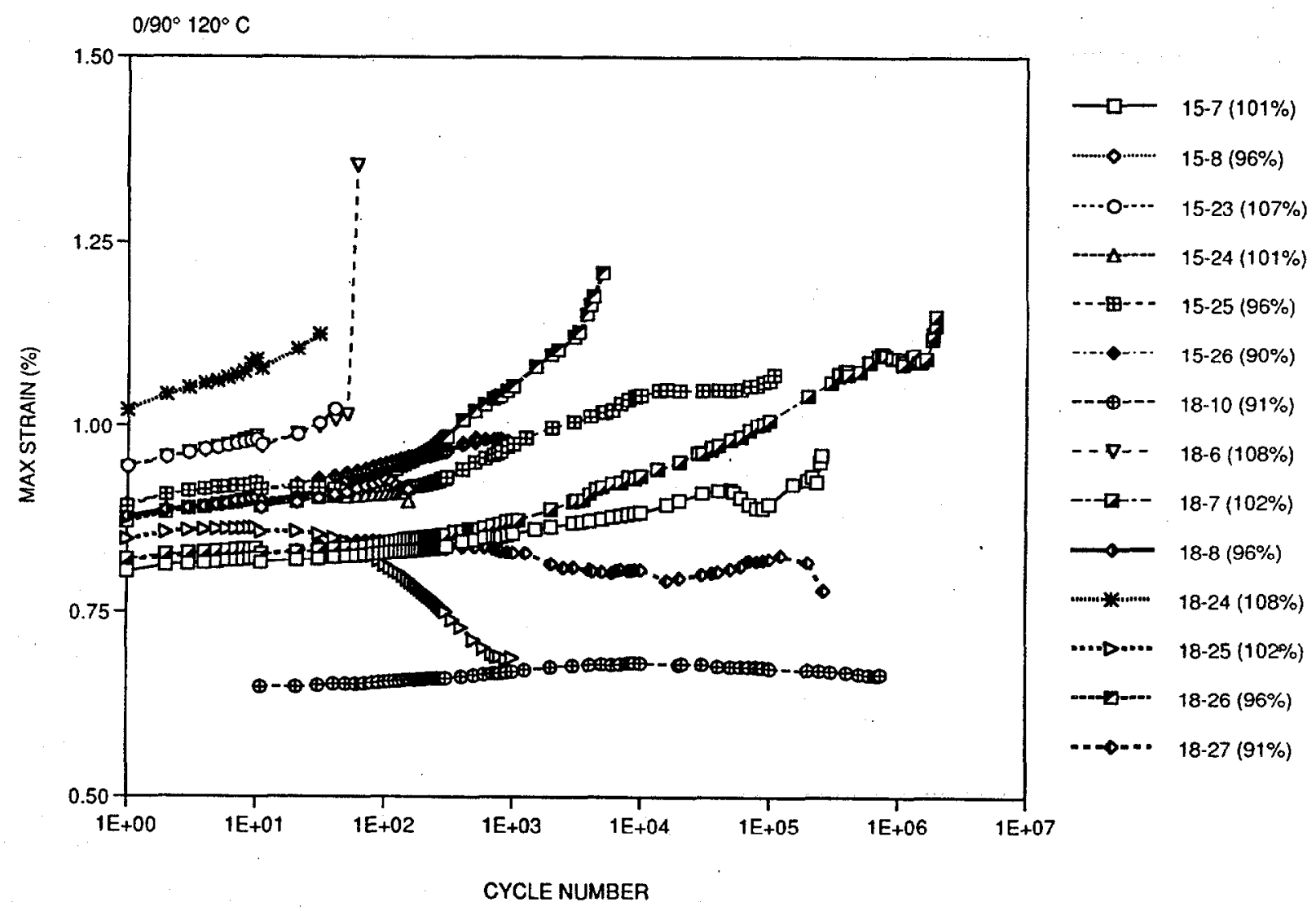

Fig. B.4. Variation of maximum cyclic strain with cycling at $120^{\circ} \mathrm{C}$ for fatigue specimens with $0 / 90^{\circ}$ fiber orientation. 


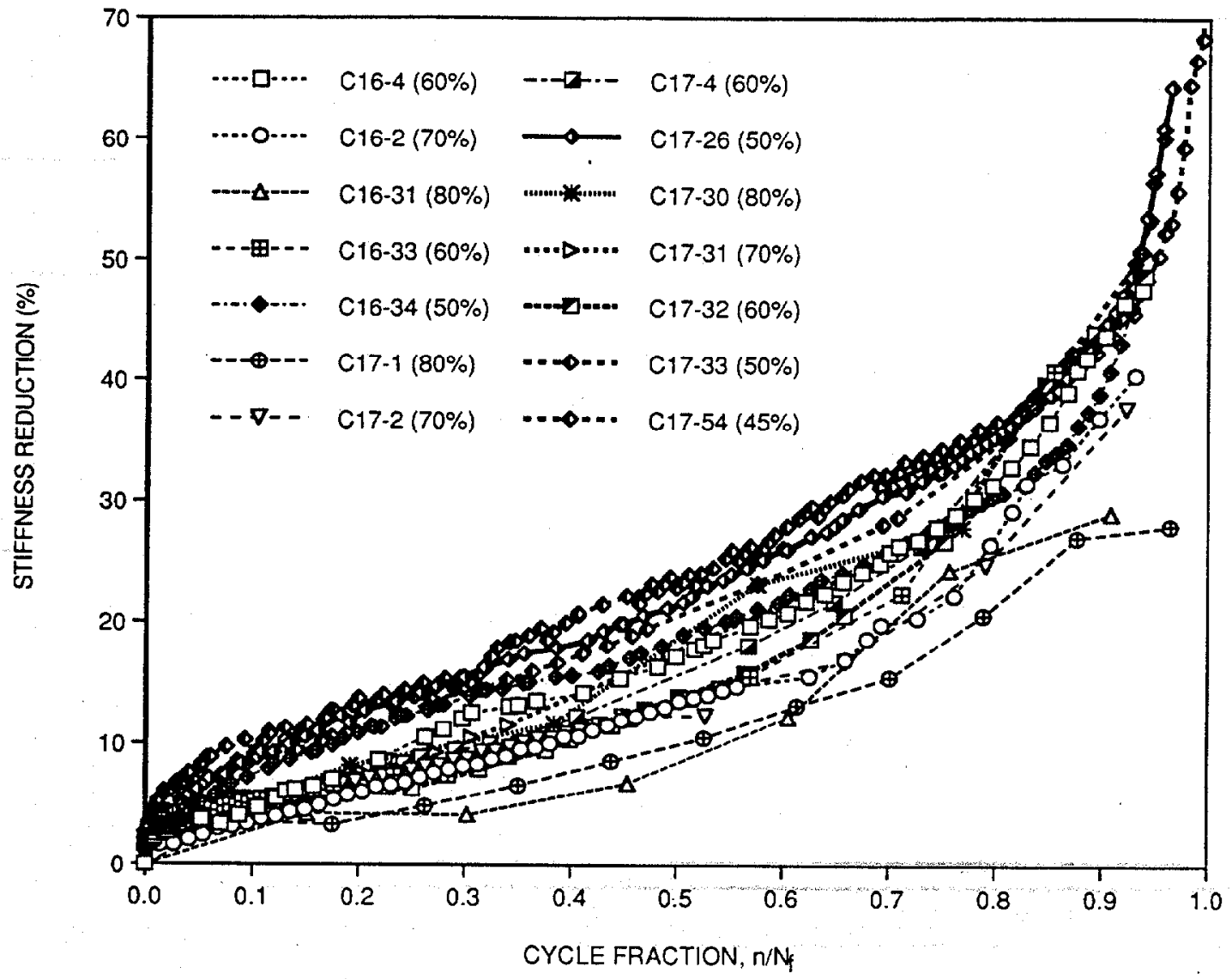

Fig. B.5. Reduction in stiffness with cycling at room temperature for fatigue specimens with $\pm 45^{\circ}$ fiber orientation. 


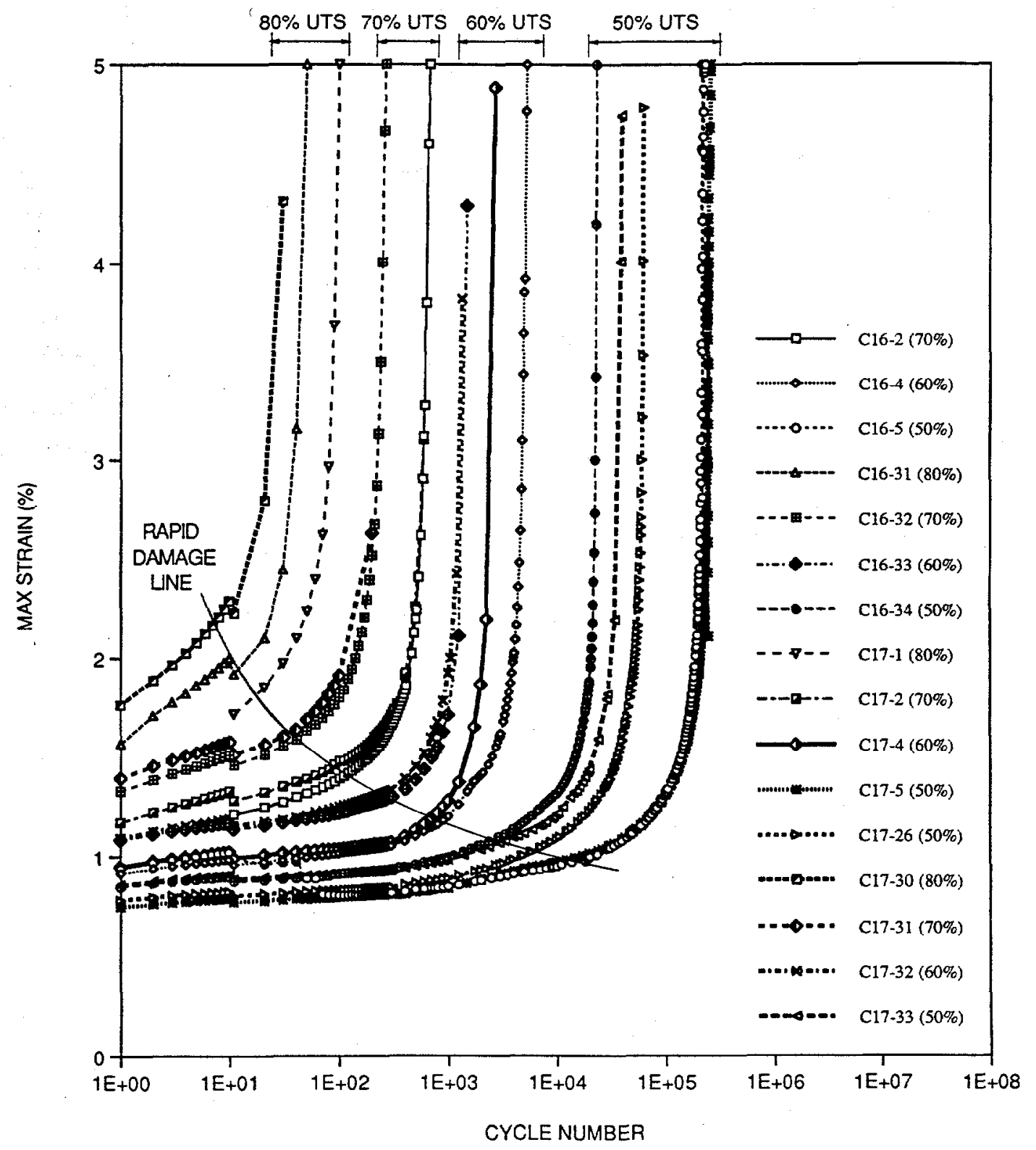

Fig. B.6. Variation of maximum cyclic strain with cycling at room temperature for fatigue specimens with $\pm 45^{\circ}$ fiber orientation. 


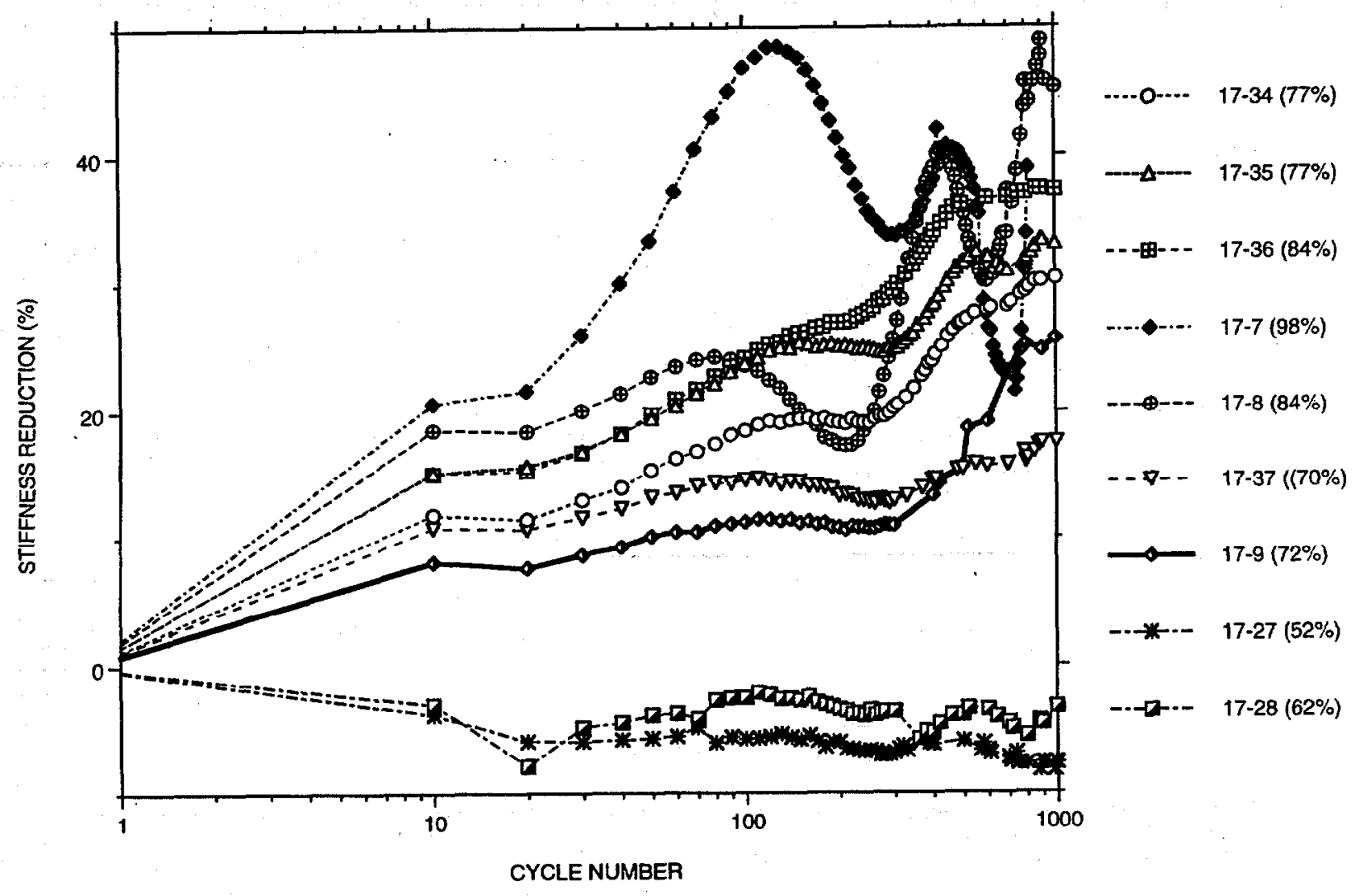

Fig. B.7. Reduction in stiffness with cycling at $120^{\circ} \mathrm{C}$ for fatigue specimens with $\pm 45^{\circ}$ fiber orientation. 


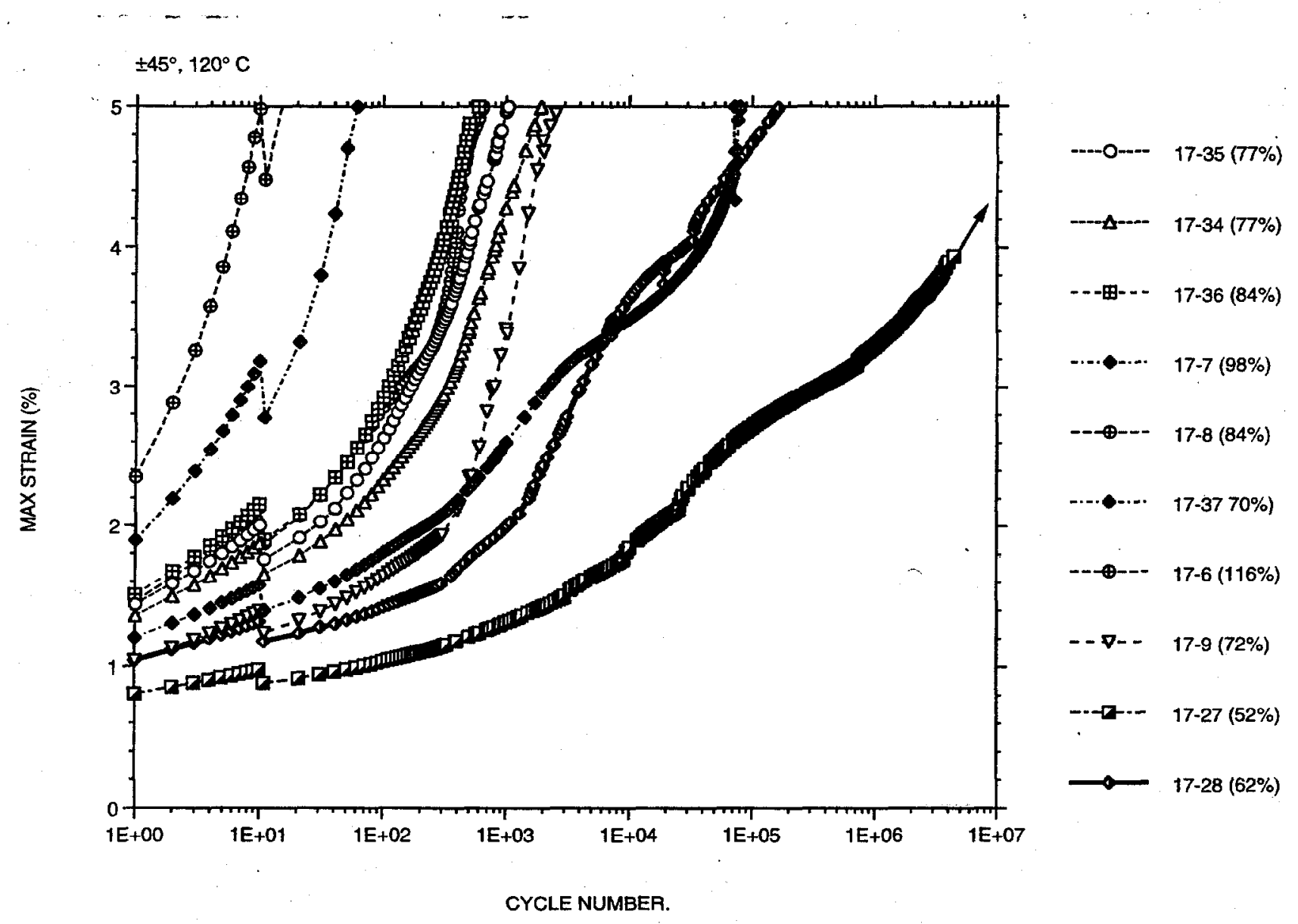

Fig. B.8. Variation in maximum cyclic strain with cycling at $120^{\circ} \mathrm{C}$ for fatigue specimens with $\pm 45^{\circ}$ fiber orientation. 


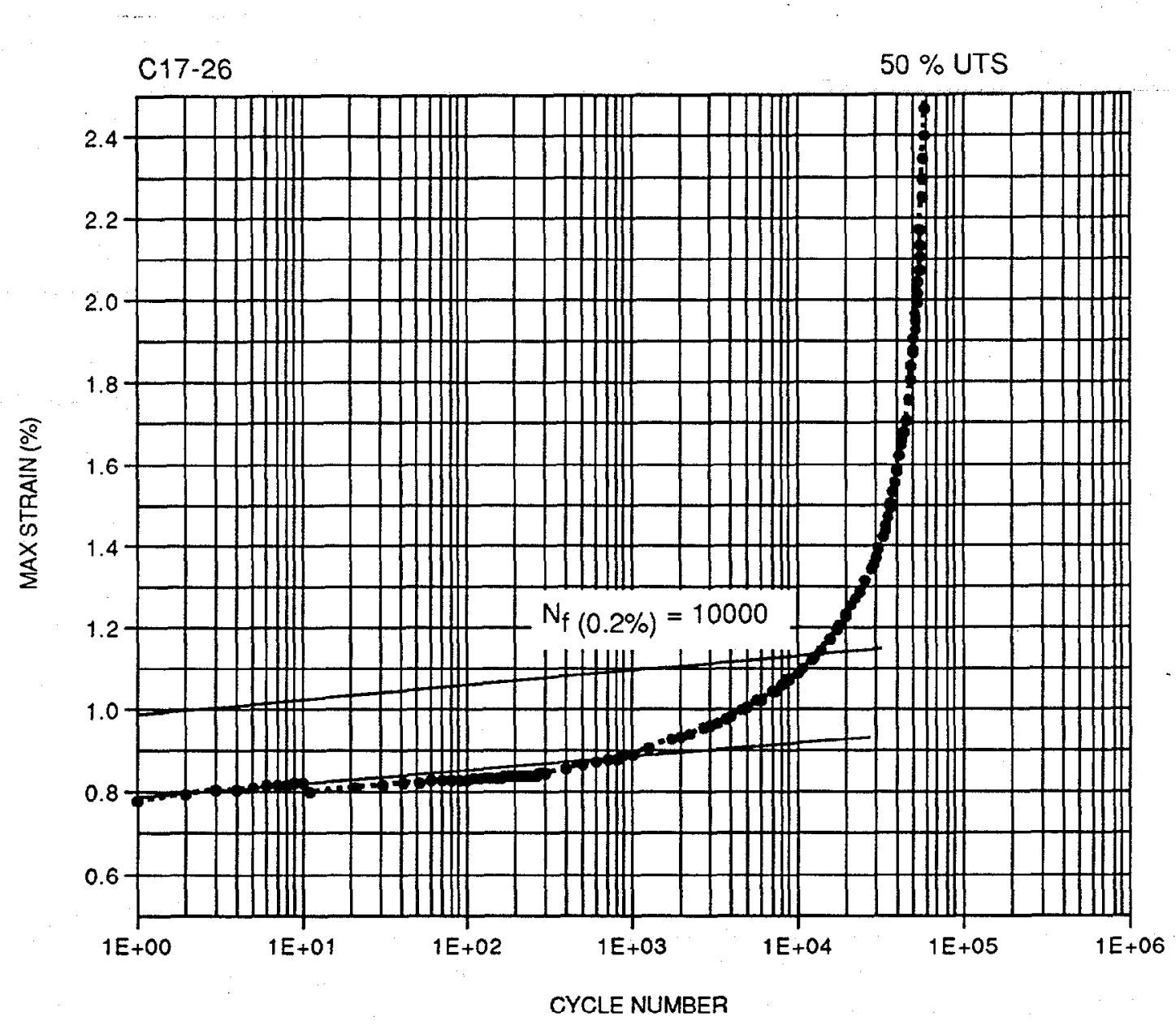

Fig. B.9. Illustration of $0.2 \%$ offset method for defining functional failure. The roomtemperature curve shown is from Fig. B.6. 
ORNL/TM-2000/29

\section{INTERNAL DISTRIBUTION}

\author{
1-2. R. L. Battiste \\ 3. R. G. Boeman \\ 4. C. R. Brinkman \\ 5-14. J. M. Corum \\ 15. W. G. Craddick \\ 16. S. Deng \\ 17. D. L. Erdman \\ 18. J. G. Hansen \\ 19. W. K. Kahl \\ 20. L. D. Klett \\ 21-22. K. C. Liu
}

\author{
23. R. E. Norris \\ 24-25. M. B. Ruggles \\ 26. S. Simunovic \\ 27. P. A. Sklad \\ 28. J. M. Starbuck \\ 29. C. D. Warren \\ 30-31. Y. J. Weitsman \\ 32. G. T. Yahr \\ 33. R. E. Ziegler \\ 34. ORNL Laboratory Records-RC \\ 35-36. ORNL Laboratory Records-OSTI
}

\section{EXTERNAL DISTRIBUTION}

37. R. S. Benson, Department of Materials Science and Engineering, The University of Tennessee, 427-C Dougherty Engineering, Knoxville, Tennessee 37922.

38. M. Elahi, 111-F Prosperity Ave., Leesburg, Virginia 20175.

39-68. E. M. Hagerman, Automotive Composite Consortium, General Motors, 30500 Mound Road, I-6, Box 9055, Warren, Michigan 48090-9055.

69. J. M. Henshaw, Department of Mechanical Engineering, The University of Tulsa, $600 \mathrm{~S}$. College Avenue, Tulsa, Oklahoma 74104-3189.

70. G. A. Holmes, National Institute of Standards and Technology, Bldg. 224, Room B116, Mail Stop: Room B108, Gaithersburg, Maryland 20899.

71. K. M. Kit, Department of Materials Science and Engineering, The University of Tennessee, 510 Dougherty Engineering, Knoxville, TN 37996-2200.

72. P. K. Liaw, Department of Materials Science and Engineering, The University of Tennessee, 427-B Doughtery Engineering, Knoxville, TN 37922.

73. K. Liechti, Engineering Mechanics Research Laboratory, Department of Aerospace Engineering and Engineering Mechanics, The University of Texas at Austin, Austin, Texas 78712.

74. T. A. Reinhart, The University of Dayton Research Institute, 300 College Park Drive, Dayton, Ohio 45469-0130.

75. W. Ren, AFRL/MLLN, 2230 Tenth St., Bldg. 655, Room 23, WPAFB, OH 45433-7817.

76. G. Sandgren, Owens Corning Science \& Technology Centre, 2790 Columbus Road, Route 16, Granville, Ohio 43023-1200.

77. C. R. Schultheisz, National Institute of Standards and Technology, Building 224, Room A209, Gaithersburg, Maryland 20899.

78. T. D. Seagrave, Bayer Corporation, 100 Bayer Road, Pittsburgh, Pennsylvania 15205.

79. L. V. Smith, Washington State University, School of Mechanics and Materials Engineering, Pullman, Washington 99164-2920.

80. X. J. Xin, Department of Mechanical and Nuclear Engineering, Kansas State University, 302 Rathbone Hall, Manhattan, KS 66506-5204.

81-84. J. A. Carpenter, U.S. Department of Energy, 1000 Independence Avenue, SW, Washington, DC 20585.

85. P. G. Patil, U.S. Department of Energy, 1000 Independence Avenue, SW, Washington, DC 20585.

86. M. Rowlins, U.S. Department of Energy, Oak Ridge Site Office, Oak Ridge, Tennessee 37831.

87. J. Russell, U.S. Department of Energy, 1000 Independence Avenue, SW, Washington, DC 20585. 


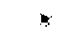

$\downarrow$ 